\title{
"La gestión indirecta de los servicios públicos. Algunos mecanismos de racionalización y control"
}

\author{
Prof. Dr. Alejandro Román Márquez \\ Departamento de Derecho Administrativo. \\ Universidad de Sevilla
}

\begin{abstract}
SUMARIO: 1. Introducción. La crisis de la gestión directa de los servicios públicos. 2. Delimitación conceptual del servicio público. Su explotabilidad por el sector privado. 3. Externalización frente a gestión indirecta de los servicios públicos. Dos modos de colaboración público-privada. 4. El contrato de colaboración entre el sector público y el sector privado. Diferencias con el contrato de gestión de servicios públicos. 5 . Problemática vinculada a los contratos de gestión de servicios públicos. 6. Mecanismos para una correcta valoración del servicio público. La revisión de precios y la prórroga del contrato. 7. Estándares de calidad en la prestación del servicio y técnicas para su aseguramiento. 8. La equidistribución del riesgo de explotación entre el contratista y la Administración. Nuevas fórmulas para la socialización de los beneficios. 9. Supervisión y control de la ejecución del contrato: la auditoría como mecanismo fundamental. 10. Reflexión final. 11. Bibliografía.
\end{abstract}

\section{RESUMEN:}

La colaboración público-privada en la gestión de los servicios públicos ha generado una gran controversia tanto en el ámbito social como jurídico. La práctica demuestra que si bien este mecanismo puede contribuir a la mejora de la eficacia administrativa, también se detectan una serie de problemas que redundan en perjuicio de la calidad global del servicio público brindado a la ciudadanía. En las siguientes páginas se expondrán las diferentes fórmulas de participación del sector privado en la actividad administrativa, la problemática más frecuente y, lo que constituye la parte esencial del presente trabajo, las fórmulas y mecanismos previstos en la propia normativa sectorial para suprimirlos o, al menos, minimizarlos, además de hacer referencia a las propuestas más interesantes formuladas desde la doctrina especializada y el ámbito comunitario. 


\section{PALABRAS GLAVE:}

Colaboración público-privada. Gestión indirecta de los servicios públicos. Externalización. Contrato de gestión de servicios públicos. Riesgo y ventura. Socialización de beneficios. Calidad global. Control. Auditoría externa.

\section{ABSTRACT:}

Public-private partnership in the management of public services has generated much controversy both in the social and legal. Practice shows that while this mechanism may contribute to the improvement of administrative efficiency, also a number of problems that are detrimental to the overall quality of public services provided to citizens are detected. In the following pages the various formulas of private sector participation in administrative activity, the most common problems and formulas and mechanisms provided for in sectoral legislation to abolish itself, or at least minimized, in addition to referring to the proposals will be discussed most interesting formulated from specialized doctrine and community level.

\section{KEYWORDS:}

Public-Private Partnerships. Indirect management of public services. Outsourcing. Contract management of public services. Risk and responsibility. Socialization benefits. Overal quality. Control. External audit.

\section{INTRODUCGIÓN. LA GRISIS DE LA GESTIÓN DIREGTA DE LOS SERVICIOS PÚBLICOS}

La crisis económica que ha azotado España y varios países del sur de Europa en el último lustro ha acelerado el proceso de privatización, externalización, gestión privada o gestión indirecta de los servicios públicos por parte de las Administraciones públicas con la finalidad manifiesta de disminuir los costes que dicha prestación supone para la hacienda pública. También han influido en este desarrollo circunstancias de tipo ideológico, vinculadas con el liberalismo económico. Este trabajo, por su naturaleza jurídica, no valorará la conveniencia u oportunidad de este mecanismo desde un punto de vista social o económico, pero sí su adaptación a la legalidad y el cumplimiento de los postulados constitucionales que ordenan la actividad gestora de los Poderes Públicos. En las páginas siguientes se va a utilizar el término "gestión indirecta" para identificar este fenómeno porque es el previsto en nuestro Ordenamiento Jurídico, y porque otros términos muy utilizados en el ámbito socio-político no son correctos por implicar características ajenas a este mecanismo. Así, el concepto de privatización se ha utilizado habitualmente para identificar la enajenación de la titularidad de un determinado bien, que pasa de manos públicas a privadas -el caso más paradigmático se ha referi- 
do tradicionalmente a la propiedad de una empresa pública-, situación que no ocurre con respecto a los servicios públicos en cuestión ${ }^{1}$. Tampoco el concepto externalización sería el más adecuado para describir este fenómeno ya que parece implicar una desvinculación completa entre la Administración titular y el prestador del servicio público, algo que, como se comprobará en este trabajo, no se produce en ningún caso. Además, este concepto se ha utilizado habitualmente para referirse a ciertas actividades referidas a la gestión ordinaria de la Administración - por ejemplo, el mantenimiento y limpieza de sus inmuebles- y no al servicio público en su conjunto ${ }^{2}$. Por último, tampoco resulta adecuado el concepto gestión privada para describir este fenómeno, ya que entre las diferentes fórmulas previstas en la normativa sobre contratación pública existen algunas en las que únicamente participará el sector privado, pero también varias en las que el sector público sigue participando en la gestión junto con el privado, por lo que debería hablarse, en propiedad, de gestión mixta.

\section{DELIMITACIÓN GONGEPTUAL DEL SERVICIO PÚBLICO. SU EXPLOTABILIDAD POR EL SECTOR PRIVADO}

La delimitación del concepto servicio público ha sido una cuestión tradicionalmente problemática en la doctrina administrativa. No es este el lugar adecuado para polemizar en torno a estas cuestiones, que escapan al objeto del presente estudio, por lo que la cuestión quedará circunscrita a determinar brevemente qué puede considerarse servicio público a los efectos de su gestión privada. Parece que el legislador se ha decantado por la concepción restringida del mismo al señalar

\footnotetext{
${ }^{1}$ Contra el abandono de la responsabilidad de garantizar un determinado servicio público, consustancial a su titularidad, ha advertido recientemente JULI PONCE, al señalar que la "[...] privatización puede comportar distintas consecuencias. En lo que ahora nos interesa, la privatización de un servicio público puede significar que la Administración deja de asumir la responsabilidad de garantizar su prestación. En otras palabras, una actividad que era servicio público, propia de la Administración Pública, deja de tener tal consideración.". PONCE SOLÉ, J., El derecho y la (ir)reversibilidad limitada de los derecho sociales de los ciudadanos. Las líneas rojas constitucionales a los recortes y la sostenibilidad social, Instituto Nacional de Administración Pública, Colección Monografías, 2013, Madrid, pág. 46. La gestión indirecta de un servicio público en ningún caso afecta a su titularidad ni, por ende, a las obligaciones implícitas en la misma.

${ }^{2}$ Sobre este concepto vid., entre otros, VIÑAS XIFRA, J., "Causas para externalizar servicios en la Administración pública", en Presupuesto y Gasto Público, n ${ }^{\circ}$ 66, Instituto de Estudios Fiscales, Madrid, 2012, págs. 167 y ss; LAGUNA DE PAZ, J. C., "Regulación, externalización de actividades administrativas y autorregulación", en la Revista de Administración Pública, n 185, 2011, págs. 89 y ss; o NAVARRO RODRÍGUEZ, P., "La externalización de la función de control en materia de energías renovables, ahorro y eficiencia energéticas en Andalucía", en Actualidad Administrativa, n 4, 2012.
} 
que "[e]n ningún caso podrán prestarse por gestión indirecta los servicios que impliquen ejercicio de la autoridad inherente a los poderes públicos." (art. 275.1 del Texto Refundido de la Ley de Contratos del Sector Público, en adelante TRLCSP), excluyéndose de esta posibilidad lo que la doctrina italiana denominó funciones públicas, que, como es sabido, abarcan todas las actividades desarrolladas por los Poderes Públicos desde una posición de supremacía y destinadas a beneficiar a la colectividad en su conjunto (administración de justicia, cuerpos y fuerzas de seguridad del estado, recaudación de tributos, etc), y que coincide con lo que parte de la doctrina ha denominado concepción amplia de servicio público.

Además, para que pueda hablarse estrictamente de servicio público es necesario que la titularidad del sector o actividad haya sido asumida legalmente por la Administración Pública - publicatio-, impidiéndose a partir de ese momento que los particulares operen en dicho ámbito, salvo que la propia Administración se lo permita expresamente a través de cualesquiera de las técnicas autorizatorias tradicionales. Así lo advierte el Texto Refundido de la Ley de Contratos del Sector Público: "[a]ntes de proceder a la contratación de un servicio público, deberá haberse establecido su régimen jurídico, que declare expresamente que la actividad de que se trata queda asumida por la Administración respectiva como propia de la misma, atribuya las competencias administrativas, determine el alcance de las prestaciones en favor de los administrados, y regule los aspectos de carácter jurídico, económico y administrativo relativos a la prestación del servicio." (art. 132); y lo recuerda la Junta Consultiva de Contratación Administrativa del Estado, al señalar que para que una actividad pueda ser gestionada por el sector privado a través del tipo contractual reservado para la gestión indirecta de los servicios públicos por la normativa sectorial - contrato de gestión de servicio público- resulta imprescindible que la Administración venga obligada legalmente a su prestación o la haya asumido como propia, además de haber determinado con carácter previo su régimen jurídico básico ${ }^{3}$. En caso contrario no podrá considerarse que el objeto del contrato recae sobre un servicio público, sino sobre otros aspectos de la actividad administrativa o de la realidad económica, como se comprobará en los epígrafes siguientes.

\footnotetext{
${ }^{3} \mathrm{El}$ informe $\mathrm{n}^{\circ}$ 26/2007, de 5 de julio de 2007, analiza la naturaleza de la actividad de un tanatorio municipal en orden a establecer si se trata de un servicio público, respondiendo la Junta Consultiva en sentido afirmativo al considerar que debe "[...] ser calificado[...] como contrato [...] de gestión de servicios públicos, a la luz de lo establecido en el artículo 155.2 y 158 de la Ley de Contratos de las Administraciones Públicas siempre que, tal y como se indica en el informe de 26 de marzo de 2007, el Ayuntamiento haya determinado con carácter previo el régimen jurídico básico propio del respectivo servicio y, este (sic) le venga impuesto con carácter de mínimo o haya sido asumido como tal servicio por el Ayuntamiento, de conformidad con los artículos 25 y 26 de la Ley 7/1985, de 2 de abril, Reguladora de las bases del régimen local.". Con ocasión de un contrato para la limpieza viaria y recogida de residuos sólidos urbanos vid. ad exemplum, el Informe de la JCGA de Valencia n ${ }^{\circ}$ 4/2012, de 4 de mayo.
} 
Por último, y a diferencia de lo que ocurría con la regulación anterior ${ }^{4}$, actualmente no es necesario que los servicios públicos tengan contenido económico, pudiendo ser gestionados, además, tanto por empresas como por particulares. La supresión del requisito del contenido económico del servicio público para poder ser gestionado por el sector privado permite que actividades que no consisten en la oferta de bienes o servicios en un determinado mercado ${ }^{5}$ también puedan ser objeto de gestión indirecta, como ocurre con los servicios de carácter social (piénsese, por ejemplo, en la asistencia domiciliaria o en los programas de vivienda social) o determinados servicios de naturaleza cultural.

\section{EXTERNALIZAGIÓN FRENTE A GESTIÓN INDIRECTA DE LOS SERVICIOS PÚBLICOS. DOS MODOS DE COLA- BORAGIÓN PÚBLICO-PRIVADA}

Si bien, como se ha señalado, las técnicas de externalización y gestión indirecta de servicios públicos generan habitualmente confusión en la opinión pública, que no tiene una idea clara de las diferencias y similitudes entre ambas, en el ámbito jurídico tales problemas no se producen ya que la normativa sectorial distingue perfectamente ambas figuras, atribuyéndole un papel específico y diferenciado de la contraria. Así, el Texto Refundido de la Ley de Contratos del Sector Público prevé un tipo contractual específico para cada una de estas técnicas. La externalización de actividades administrativas encuentra acomodo en el contrato de servicios, regulado por esta norma en sus artículos 10 y 301 a 312, entre otros. La recientemente aprobada Directiva 2014/24/CE, del Parlamento Europeo y del Consejo, de 26 de febrero de 2014, sobre contratación pública y por la que se deroga la Directiva 2004/18/CE, define a los contratos públicos de servicios como "los contratos públicos cuyo objeto sea la prestación de servicios distintos de aquellos a los que se refiere el punto 6 [contrato de obras]" (art. 2.1 punto 9). Por su parte, el Texto Refundido de la Ley de Contratos del Sector Público sigue la técnica europea y los define como "[...] aquéllos cuyo objeto son prestaciones de hacer consistentes en el desarrollo de una actividad o dirigidas a la obtención de un resultado distinto de una obra o un suministro. A efectos de aplicación de esta Ley, los contratos de servicios se dividen en las categorías enumeradas en el Anexo II" (art. 10) ${ }^{6}$.

\footnotetext{
${ }^{4}$ Señalaba el artículo 155.1 del derogado Real Decreto 2/2000, de 16 de junio, por el que se aprueba el texto refundido de la Ley de Contratos de la Administración, que "[1] a Administración podrá gestionar indirectamente, mediante contrato, los servicios de su competencia, siempre que tengan un contenido económico que los haga susceptibles de explotación por empresarios particulares. [...]".

${ }^{5}$ Ésta es, precisamente, la definición de servicio de naturaleza económica proporcionada por el Libro Verde sobre los Servicios de Interés General, advirtiendo sobre este asunto que "La distinción entre acti-
} 
Una de las características esenciales del contrato de servicios es su prestación directa a favor de la Administración - y no a favor de los particulares, al menos no mayoritariamente, como ocurre en la modalidad siguiente, el contrato de gestión de servicio público- y la retribución directa al contratista por parte de aquélla. Sin embargo, como advierte MORENO MOLINA ${ }^{7}$, este criterio resulta insuficiente para establecer una diferenciación efectiva entre el contrato de servicios y el contrato de gestión de servicios públicos. La Junta Consultiva de Contratación Administrativa del Estado ${ }^{8}$ entiende que cuando el contratista asume la organización y el riesgo derivado de las actividades precisas para la prestación de un servicio se tratará de un contrato de gestión de servicio público. En caso contrario deberá calificarse como un mero contrato de servicios, aunque sigan existiendo supuestos dudosos difíciles de encuadrar en una u otra figura, y cuya solución jurisprudencial pasa por considerarlos contratos atípicos o especiales ${ }^{9}$.

Por su parte, la gestión indirecta de los servicios públicos se realiza a través del citado contrato de gestión de servicios públicos, previsto en los artículos 8 y 275 y ss TRLCSP. Para la norma que regula la contratación pública, esta figura contrac-

vidades económicas y actividades no económicas es, por tanto, dinámica y está en evolución constante. Un número cada vez mayor de actividades ha adquirido relevancia económica a lo largo de las últimas décadas, al tiempo que se difuminaba esta distinción para un número cada vez mayor de servicios. En su Comunicación de 2000, la Comisión presentó una serie de ejemplos de actividades no económicas. Estos ejemplos atañen especialmente a cuestiones que son intrínsecamente prerrogativa del Estado, como la educación nacional y los regímenes básicos de seguridad social obligatorios, y a ciertas actividades ejercidas por organismos cuyas funciones son esencialmente sociales y que no tienen por objeto emprender actividades industriales o comerciales. Dado que esta distinción no es estática en el tiempo, la Comisión destacó, en su Informe al Consejo Europeo de Laeken, que no sería ni posible ni deseable elaborar a priori una lista definitiva de todos los servicios de interés general que deben considerarse «no económicos»". Comisión Europea, Libro Verde sobre los Servicios de Interés General, presentado por la Comisión el 21 de mayo de 2003, COM (2003) 270 final, págs. 15 y 16. En cualquier caso, esta distinción perdió toda su importancia en materia de contratación a partir de la eliminación del citado requisito.

${ }^{6}$ La sentencia del Tribunal Supremo de 19 de febrero de 1999 (Sala de lo Contencioso-Administrativo, Sección $7^{\mathrm{a}}$ ) establece claramente la distinción entre los objetos del contrato de obras y de servicios: "En los contratos de obra el empresario se obliga a realizar una obra, es decir, el resultado de un trabajo mediante la contraprestación de una remuneración, mientras que en el contrato de servicios el arrendatario se obliga, no a ejecutar la obra, sino a prestar un servicio, o lo que es lo mismo, se promete el trabajo en cuanto tal y no el resultado que ha de producir ese trabajo, de conformidad con lo dispuesto en el artículo 1544 del Código Civil en relación con los artículos 4, 44 y 62 de la Ley de Contratos del Estado de 8 de abril de 1965.". (Fundamento de Derecho Tercero).

7 MOREnO MOLINA, J. A. y PLEITE GUADAMILLAS, F., La nueva Ley de Contratos del Sector público. Estudio sistemático, $3^{\mathrm{a}}$ edición, La Ley, 2011, pág. 332.

${ }^{8}$ Informes n ${ }^{\circ}$ 04/08, de 28 de julio de 2008; y 65/08, de 31 de marzo de 2009, entre otros.

${ }^{9}$ Este autor hace referencia a la sentencia del Tribunal Superior de Justicia de Murcia de 23 de junio de 2001, que califica de esta forma un contrato de prestación de cafeterías para el personal y público en general del Hospital Universitario Virgen de la Arrixaca (Murcia). 
tual tiene lugar cuando "[...] una Administración Pública [...], encomienda a una persona, natural o jurídica, la gestión de un servicio cuya prestación ha sido asumida como propia de su competencia por la Administración [...] encomendante" (art. 8.1 TRLCSP); cuidándose especialmente de advertir que no se considerará como tal, y por tanto no serán aplicables los preceptos contenidos en esta Ley para esta modalidad contractual, cuando "[...] la gestión del servicio público se efectúe mediante la creación de entidades de derecho público destinadas a este fin, ni a aquellos en que la misma se atribuya a una sociedad de derecho privado cuyo capital sea, en su totalidad, de titularidad pública" (art. 8.2 TRLCSP). Y no podría ser de otro modo porque, como se ha señalado, la gestión indirecta de los servicios públicos, finalidad para la que fue creada esta modalidad contractual, exige que éstos se encomienden a personas físicas o jurídicas diferentes de la Administración, lo que no ocurre en el supuesto recogido por el artículo 8.2 TRLCSP. En los casos excluidos por esta Ley sigue existiendo gestión directa, si bien ejecutada a través de entes instrumentales de la Administración, tal y como señala expresamente el artículo 85 LRBRL. Además, el propio artículo 275 TRLCSP dispone con carácter general que "La Administración podrá gestionar indirectamente, mediante contrato, los servicios de su competencia, siempre que sean susceptibles de explotación por particulares.", excluyendo de esta posibilidad únicamente aquellos "[...] servicios que impliquen ejercicio de la autoridad inherente a los poderes públicos.", lo que, aún en el caso de no existir esta previsión legal, resultaría de todas formas imposible -jurídicamente- a la vista del artículo 9.2 de la Ley 7/2007, de 12 de abril, del Estatuto Básico del Empleado Público (en adelante, EBEP) ${ }^{10}$.

Debe tenerse en cuenta igualmente que la entrada del sector privado en la explotación de los servicios públicos puede revestir diferentes modalidades, tal y como prevé el propio artículo 277 TRLCSP, cuya elección quedará a la libre apreciación de la Administración contratante, con la única obligación de justificar motivadamente su decisión, al tratarse del ejercicio de una potestad discrecional

\footnotetext{
${ }^{10}$ Como se recordará, este precepto dispone que "[...] el ejercicio de las funciones que impliquen la participación directa o indirecta en el ejercicio de las potestades públicas o en la salvaguardia de los intereses generales del Estado y de las Administraciones Públicas corresponden exclusivamente a los funcionarios públicos, en los términos que en la ley de desarrollo de cada Administración Pública se establezca.", con la única excepción del personal de los organismos portuarios. Las empresas privadas, por su propia naturaleza, carecen de esta categoría laboral, por lo que en ningún caso podrán ejercitar dicha autoridad inherente a los poderes públicos, instrumentalizadas a través de potestades públicas. En el mismo sentido, el artículo 92.3 LRBRL recuerda este precepto para el ámbito local, señalando que "[c]orresponde exclusivamente a los funcionarios de carrera al servicio de la Administración local el ejercicio de las funciones que impliquen la participación directa o indirecta en el ejercicio de las potestades públicas o en la salvaguardia de los intereses generales. Igualmente son funciones públicas, cuyo cumplimiento queda reservado a funcionarios de carrera, las que impliquen ejercicio de autoridad, y en general, aquellas que en desarrollo de la presente Ley, se reserven a los funcionarios para la mejor garantía de la objetividad, imparcialidad e independencia en el ejercicio de la función.".
} 
(art. 54.1 f) LRJPAG). Y es que, como señaló MARTÍNEZ PALLARÉS, en nuestro Ordenamiento Jurídico no existe la categoría contractual "contrato de gestión de servicios públicos", sino "[...] una mera técnica de gestión que se concreta en una pluralidad contractual diferenciada [...] a través de la que es posible dar cabida a todo tipo de gestión indirecta de un determinado servicio público." "11. Cuatro son las modalidades de contratación a disposición de la Administración: concesión - por la que el empresario gestiona el servicio público a su riesgo y ventura-, gestión interesada -en la que tanto la Administración como el empresario participarán en los resultados de la explotación del servicio público en la proporción que se establezca en el contrato-, concierto - con persona natural o jurídica que venga realizando prestaciones análogas al servicio público en cuestión- y sociedad de economía mixta - en la que participe la Administración por sí misma o a través de un ente instrumental en concurrencia con personas naturales o jurídicas (art. 277 TRLCSP).

Recapitulando brevemente lo expuesto hasta este momento, se pueden diferenciar dos formas de participación del sector privado en la actividad pública, previstas ambas en la normativa sobre contratación pública: si su objeto es un servicio público globalmente considerado, asumido como tal por la Administración tanto por imperativo legal como voluntariamente, cuya organización y riesgo son asumidos por el sector privado, que presta sus servicios directamente a los ciudadanos, siendo remunerado mayoritariamente por la Administración contratante; se trata de un contrato de gestión de servicio público. Por el contrario, si la actividad no puede considerarse como un servicio público en sentido estricto y se presta directamente a la Administración, quien remunera a la empresa privada; se trata de un contrato de servicios ${ }^{12}$. Únicamente el primero de éstos será objeto de estudio por haber sido el centro de una agria polémica en torno a la mal llamada privatización de los servicios públicos.

Pero, además, el Texto Refundido de la Ley de Contratos del Sector Público

${ }^{11}$ MARTÍNEZ PALLARÉS, P.L., "Particularidades del contrato de gestión de servicios públicos. En particular su regulación en el ámbito local”, en Cuadernos de Derecho Local, Fundación Democracia y Gobierno Local, n², 2003, pág. 150. Para este autor, "[e]l legislador ha extraído del tradicional régimen jurídico de la concesión una serie de prescripciones, y las ha generalizado, con el dudoso resultado de que algunas de ellas son de imposible cumplimiento en alguna de las modalidades contractuales [...]”.

${ }^{12} \mathrm{Si}$, por el contrario, el objeto del contrato tampoco fuese un servicio público, se prestase igualmente de forma directa a los ciudadanos, pero la remuneración no proviniese principalmente de la administración sino de sus usuarios ( $v . g r$. un aparcamiento público), no se estaría ante un contrato de servicios sino ante una concesión de dominio público, que no se regula por la normativa de contratación pública, sino por la relativa al patrimonio de las Administraciones Públicas. Así lo reconoce la jurisprudencia comunitaria: por todas, la STJUE de 13 de octubre de 2005 (asunto G458/2003). 
prevé otras modalidades de contratación cuyo objeto puede coincidir, en determinados casos, con los tipos contractuales expuestos hasta el momento, por lo que es necesario proporcionar someramente las claves necesarias para su correcta diferenciación.

\section{EL GONTRATO DE COLABORAGIÓN ENTRE EL SECTOR PÚBLICO Y EL SECTOR PRIVADO. DIFERENGIAS GON EL CONTRATO DE GESTIÓN DE SERVICIOS PÚBLICOS}

La Ley 30/2007, de 30 de octubre, de Contratos del Sector Público, introduce un nuevo tipo contractual en el Ordenamiento Jurídico español: el contrato de colaboración entre el sector público y el sector privado. El actual Texto Refundido de esta norma lo define como aquél "[...] en que una Administración Pública o una Entidad pública empresarial u organismo similar de las Comunidades Autónomas encarga a una entidad de derecho privado, por un periodo determinado en función de la duración de la amortización de las inversiones o de las fórmulas de financiación que se prevean, la realización de una actuación global e integrada que, además de la financiación de inversiones inmateriales, de obras o de suministros necesarios para el cumplimiento de determinados objetivos de servicio público o relacionados con actuaciones de interés general, comprenda alguna de las siguientes prestaciones: [1] a construcción, instalación o transformación de obras, equipos, sistemas, y productos o bienes complejos, asi como su mantenimiento, actualización o renovación, su explotación o su gestión [;] [1] a gestión integral del mantenimiento de instalaciones complejas [;] [1] a fabricación de bienes y la prestación de servicios que incorporen tecnología específicamente desarrollada con el propósito de aportar soluciones más avanzadas y económicamente más ventajosas que las existentes en el mercado [; u] [o] tras prestaciones de servicios ligadas al desarrollo por la Administración del servicio público o actuación de interés general que le haya sido encomendado." (art. 11.1). Su objeto es, como se desprende de su definición legal, ciertamente impreciso y difícil de deslindar de otros tipos contractuales como el contrato de concesión de obra pública $^{13}$ o el contrato de gestión de servicios públicos.

${ }^{13}$ Ya que debe recordarse que el objeto de este tipo de contratos públicos consiste precisamente en "[...] la realización por el concesionario de algunas de las prestaciones a que se refiere el artículo 6, incluidas las de restauración y reparación de construcciones existentes, así como la conservación y mantenimiento de los elementos construidos, y en el que la contraprestación a favor de aquél consiste, o bien únicamente en el derecho a explotar la obra, o bien en dicho derecho acompañado del de percibir un precio.", pudiendo incluir, igualmente, "[...] La adecuación, reforma y modernización de la obra para adaptarla a las características técnicas y funcionales requeridas para la correcta prestación de los servicios o la realización de las actividades económicas a las que sirve de soporte material. Las actuaciones de reposición y gran reparación que sean exigibles en relación con los elementos que ha de reunir cada una de las obras para mantenerse apta a fin de que los servicios y actividades a los que aquéllas sirven puedan ser desarrollados adecuadamente de acuerdo con las exigencias económicas y las demandas sociales." (art. 7.1 y 2 TRLCSP); por lo que coincide parcialmente con el objeto del contrato de colaboración entre el sector público y el sector privado. 
La clave para diferenciar esta figura del contrato de concesión de obra pública la proporciona el legislador al señalar que "[] a contraprestación a percibir por el contratista colaborador consistirá en un precio que se satisfará durante toda la duración del contrato, y que podrá estar vinculado al cumplimiento de determinados objetivos de rendimiento." (art. 11.4 TRLCSP); mientras que en el contrato de concesión de obra pública la contraprestación principal consiste en la remuneración directa por parte de los usuarios del servicio, y no, por tanto, en los pagos directos por parte del socio público. En cualquier caso, se trata de un tipo contractual de aplicación subsidiaria o residual, pues el propio Texto Refundido de la Ley de Contratos del Sector público advierte, justo después de definir su objeto, que "[s]ólo podrán celebrarse contratos de colaboración entre el sector público y el sector privado cuando previamente se haya puesto de manifiesto, en la forma prevista en el artículo $118^{14}$, que otras fórmulas alternativas de contratación no permiten la satisfacción de las finalidades públicas" (art. 11.2 TRLCSP).

Este carácter residual marca el elemento esencial de esta modalidad contractual, ya que implica en todo caso un cierto nivel de complejidad en las prestaciones objeto del contrato, se señale o no expresamente en las posibilidades del artículo 11.1 TRLCSP, ya que, como recuerda la Junta Consultiva de Contratación Administrativa del Estado ${ }^{15}$, aunque "[d]e este precepto no se deduce que la Ley exija de modo expreso y para todos los casos la indicada complejidad, sino que la liga en particular a la conservación o a la gestión de determinados bienes o instalaciones, pero sin hacer referencia a ella en relación con el resto de las prestaciones que pueden ser objeto del contrato. Ello no obstante, debe tenerse en cuenta, en primer lugar, el hecho de que el apartado 2 del mismo artículo 11 exige que para poder configurar el contrato bajo este tipo específico, "previamente se haya puesto de manifiesto... que otras fórmulas alternativas de contratación no permiten la satisfacción de las finalidades públicas", lo que implícitamente nos lleva a entender que la complejidad de la prestación si es un requisito de este contrato, pues cuando se trate de prestaciones, no complejas, evidentemente podrá satisfacerse la necesidad de que se trate a través de cualquiera de las otras figuras contractuales que la Ley contempla.". Además, el sistema de adjudicación previsto para este tipo de contratos ${ }^{16}$ está configurado específicamente

${ }^{14}$ Se refiere al documento de evaluación que deberá realizar la Administración en la fase previa del procedimiento de contratación y que deberá poner de manifiesto que, "[...] habida cuenta de la complejidad del contrato, no se encuentra en condiciones de definir, con carácter previo a la licitación, los medios técnicos necesarios para alcanzar los objetivos proyectados o de establecer los mecanismos jurídicos y financieros para llevar a cabo el contrato, y se efectúe un análisis comparativo con formas alternativas de contratación que justifiquen en términos de obtención de mayor valor por precio, de coste global, de eficacia o de imputación de riesgos, los motivos de carácter jurídico, económico, administrativo y financiero que recomienden la adopción de esta fórmula de contratación".

${ }^{15}$ Informe n ${ }^{\circ} 53 / 09$, de 26 de febrero de 2010.

16 "Los contratos de colaboración entre el sector público y el sector privado a que se refiere el artículo 11 se adjudicarán por este procedimiento, sin perjuicio de que pueda seguirse el procedimiento negociado con publicidad en el caso previsto en el artículo 154.a.". (art. 164.3 TRLCSP). 
para contratos complejos, tal y como señala expresamente el artículo 180.1 TRLCSP: "El diálogo competitivo podrá utilizarse en el caso de contratos particularmente complejos, cuando el órgano de contratación considere que el uso del procedimiento abierto o el del restringido no permite una adecuada adjudicación del contrato.". Nada obsta, por tanto, que un servicio público sea gestionado a través de un contrato de colaboración entre el sector público y el sector privado, siempre que ostente un grado mínimo de complejidad y que la contraprestación principal consista en el pago de un precio por parte del socio público.

Pero ¿qué se considera una prestación compleja? ¿cuándo puede definirse un contrato como complejo, permitiendo el recurso a esta modalidad contractual? El artículo 180.4 TRLCSP considera que un contrato es particularmente complejo "[...] cuando el órgano de contratación no se encuentre objetivamente capacitado para definir [...] los medios técnicos aptos para satisfacer sus necesidades u objetivos, o para determinar la cobertura jurídica o financiera de un proyecto.", por lo que la complejidad de estos contratos puede venir justificada tanto por cuestiones materiales -especificaciones técnicas- como jurídicas e, incluso, financieras. Deberá analizarse caso por caso si concurre esta circunstancia para que un servicio público pueda ser gestionado a través de esta figura ${ }^{17}$.

\section{PROBLEMÁTICA VINGULADA A LOS CONTRATOS DE GESTIÓN DE SERVICIOS PÚBLICOS}

Una vez expuestas las diferentes posibilidades que permite el legislador para gestionar los servicios públicos a través del sector privado y sus figuras afines, es posible centrarse en la figura del contrato de gestión de servicios públicos y sus principales problemas jurídicos y sociales:

a) Uno de los primeros y principales problemas relacionados con la gestión indirecta de los servicios públicos es la incorrecta valoración de los mismos. En es-

${ }^{17}$ Un ejemplo de servicio público gestionado mediante un contrato de colaboración entre el sector público y el sector privado es la Ciudad de la Justicia de Córdoba, contrato denominado por la Consejería de Gobernación y Justicia de la Junta de Andalucía como de "constitución de un derecho de superficie para la construcción, conservación y explotación de un edificio destinado a ser la ciudad de la justicia de Córdoba mediante arrendamiento a la Comunidad Autónoma de Andalucía" (Expte. 34/11/6); y que fue considerado como tal por el Tribunal Administrativo de Recursos Contractuales de esta Comunidad Autónoma (Resolución n ${ }^{\circ}$ 24/2012). También son gestionados habitualmente a través de esta figura contractual los denominados Centros Hospitalarios de Alta Resolución (CHARES), existiendo actualmente trece de éstos en Andalucía: El Toyo, Puente Genil, Valle del Guadiato, Guadix, Loja, Sierra de Segura, Alcaudete, Alcalá la Real, Benalmádena, Utrera, Écija, Morón y Sierra Norte. 
tos casos, el contratista presiona a la Administración para que los servicios a prestar sean valorados al alza, por encima de su precio real, para que las tarifas a pagar por parte de los usuarios sean más altas o el eventual canon a satisfacer a la Administración más bajo, incrementando sus beneficios de forma artificial. No es, por tanto, inhabitual que el servicio prestado a los ciudadanos se encarezca artificialmente, debido a que en muchas ocasiones se parte de una valoración del mismo que se sitúa por encima de su coste real ${ }^{18}$.

b) Relacionado con el anterior, si bien puede constituir un problema autónomo, está el aumento del coste del servicio para los ciudadanos. Viene siendo habitual que las tarifas a pagar por los usuarios de los servicios públicos gestionados de forma indirecta se encarezcan progresivamente a medio y largo plazo ${ }^{19}$. La experiencia ha demostrado cómo en ocasiones - no siempre- tales tarifas han duplicado o incluso triplicado su cuantía, encareciendo su utilización para los ciudadanos, lo que produce una merma en su nivel de vida.

c) También se aprecia, en ciertos casos, una bajada de la calidad global del servicio prestado a los usuarios. En tales casos el grado de satisfacción de los usuarios se ha visto afectado negativamente con respecto a situaciones anteriores en las que el servicio público era prestado utilizando alguna de las modalidades de gestión directa, y especialmente cuando se utilizaba la primera de las posibilidades del artículo 85 LRBRL. Una deficiente configuración de los pliegos del contrato de gestión de servicios públicos junto con una eventual culpa in vigilado por parte de la Administración titular del mismo son las causas habituales de que los

${ }^{18}$ Llegando, en casos extremos, a una auténtica desidia -interesada o no- a la hora de controlar el coste de los servicios contratados. El Tribunal de Cuentas, con ocasión de la fiscalización de la contratación realizada por los municipios con ocasión del Fondo Estatal de Inversión Local, señalaba que "[d] ado que las entidades ya contaban con el $100 \%$ de la financiación sobre el presupuesto presentado, de forma que si, tras el proceso de licitación, la adjudicación se realizaba por un precio inferior, la cantidad que recibirían sería menor que la autorizada, las entidades no tenían un interés directo en que se produjeran bajas sobre el precio de licitación, puesto que este resultado no iba a repercutir en su presupuesto de forma directa.; [...] [e]l $53 \%$ de los contratos se adjudicaron sin baja en la licitación y el resto registraron una baja del 8,05\%. No obstante, la baja efectiva de estos contratos, se redujo hasta el 2,46\%. [.... Respecto del procedimiento utilizado en la contratación, en los contratos adjudicados mediante el procedimiento abierto, la baja obtenida fue sensiblemente mayor". Informe del Tribunal de Cuentas n ${ }^{\circ} 948$ de Fiscalización de las contrataciones desarrolladas por las Entidades Locales en relación con las inversiones financiadas por el Fondo Estatal de Inversión Local creado por Real Decreto-Ley 9/2008, de 28 de noviembre; 26 de septiembre de 2012, págs. 45 y 46.

19 Sobre el cálculo de estas tarifas vid. ad exemplum trabajo de FLORES DOMÍNGUEZ, L. E., "Aspectos jurídicos del precio del agua. Especial referencia a la empresa metropolitana de aguas de Sevilla (EMASESA)", en la Revista Andaluza de Administración Pública, Instituto Andaluz de Administración Pública, nº 87, septiembre-diciembre, 2013, Sevilla, págs. 303 y ss. 
necesarios umbrales de calidad o bien no estén correctamente fijados y garantizados, o bien sean desconocidos impunemente por el contratista.

d) El envejecimiento y eventual obsolescencia de las infraestructuras vinculadas a la prestación del servicio público también puede llegar a constituir graves problemas si en los pliegos de contratación no se prevén las inversiones necesarias por parte de éste. Esta circunstancia generará una progresiva disminución de la calidad del servicio prestado a los usuarios, además de un perjuicio patrimonial a la Administración pública, ya que el contratista puede recibir unas instalaciones de titularidad pública en condiciones idóneas para la prestación del servicio público pero, por los efectos del tiempo combinado con dicha falta de inversiones para su modernización y adaptación a las necesidades del servicio, al finalizar el plazo del contrato revierten a la Administración unas instalaciones obsoletas que requerirán de una fuerte inversión para su adaptación a las necesidades actuales del servicio.

e) Estrechamente relacionado con lo anterior está el problema de la incorrecta valoración de las infraestructuras necesarias para la prestación del servicio y de su estado de conservación. Una valoración a la baja de las infraestructuras públicas puestas a disposición del contratista influye directamente en el canon a satisfacer por parte de éste, que será menor, aumentando en consecuencia sus beneficios. Por otro lado, el estado de conservación de los elementos a revertir a la Administración al finalizar el contrato - dejando a un lado su eventual obsolescencia- no suele ser evaluado tan concienzudamente como debiera, generando una pérdida patrimonial a la Administración. Similares inconvenientes se aprecian cuando las infraestructuras no fueron puestas a disposición del contratista por la Administración, sino construidas ex profeso por aquél como parte del contrato. En este caso el problema puede venir por una valoración excesiva de las obras a realizar por el contratista.

f) También genera un perjuicio patrimonial a la Administración la incorrecta valoración del canon a satisfacer por parte del contratista. Sin embargo, como se ha apuntado ya, no suele tratarse de un problema de carácter autónomo, sino generado por una incorrecta valoración de los demás elementos del contrato, que influyen a la baja en su determinación. En cualquier caso, se trate de una incorrecta valoración del canon en sí mismo o provocado por problemas vinculados a otros elementos del contrato, el perjuicio patrimonial es evidente e inaceptable.

g) Si bien no se trata de un problema de carácter jurídico, la externalización de la gestión de servicios públicos suele conllevar -si bien no necesariamenteuna disminución del personal vinculado a la prestación de los mismos. La alarma social que genera el despido de trabajadores públicos en circunstancias eco- 
nómicas como las actuales favorece la extensión de cierto rechazo social a la generalización de la figura del contrato de gestión de servicios públicos. Lo mismo ocurre con la política retributiva del personal al servicio del contratista, que igualmente puede constituir una cuestión problemática con implicaciones de carácter $\operatorname{social}^{20}$.

h) En los últimos tiempos se ha asistido a una reducción progresiva de los plazos máximos de duración de este tipo de contrato que hasta hace relativamente poco tiempo tenían una naturaleza pseudo perpetua debido a los extraordinariamente dilatados plazos de duración ${ }^{21}$. A pesar de que los plazos máximos se han reducido drásticamente en ciertas materias -fundamentalmente en el caso de contratos que comprendan la explotación de un servicio público cuyo objeto consista en la prestación de servicios sanitarios y que no incluyan la ejecución de obras, limitado a 10 años- se aprecia una tendencia al agotamiento indiscriminado de plazos máximos sin una justificación sólida. Este agotamiento sistemático de los plazos máximos permitidos por la normativa de contratación pública provoca la expulsión temporal del mercado de determinados ámbitos de la actividad económica sin causa justificada - que únicamente puede consistir en el plazo necesario para amortizar las inversiones realizadas y obtener un beneficio razonable-, menoscabando la competencia efectiva entre empresas que, además de ser un principio garantizado por la normativa sobre contratación pública, conlleva inevitablemente una bajada en la calidad del servicio prestado a los usuarios.

i) La complejidad técnica y los condicionamientos materiales de determinados servicios públicos hacen muy dificultosa su prestación ya que existen en el mercado muy pocas empresas con la infraestructura económica y técnica necesaria para ello. Así ocurre con ciertos servicios como el abastecimiento de agua potable para consumo humano, el suministro eléctrico o los relacionados con la asistencia sanitaria. Esta reducción de los posibles adjudicatarios del contrato implica un mercado de naturaleza oligopólica, lo que redunda en perjuicio de la necesaria concurrencia competitiva propugnada por la normativa sobre contratación pública.

${ }^{20}$ Sobre este y otros asuntos relacionados con la modificación de las condiciones de trabajo en el sector público como consecuencia de la crisis económica actual vid. RODRÍGUEZ ESCANCIANO, S., "Los despidos objetivos en las administraciones públicas, rescate de contratas y concesiones y supresión de entidades o estructuras administrativas", en La reforma del sector público local, Castillo Blanco, F. (Dir.) et al, Instituto García Oviedo, Universidad de Sevilla, 2014, págs. 369 y ss (en especial, págs. 384 a 393).

${ }^{21}$ La Ley de Contratos del Estado de 8 de abril de 1965 preveía un plazo máximo de concesión de 99 años. 
j) Otro problema vinculado con la propia naturaleza del contrato de gestión de servicios públicos tiene su origen en el hecho de que las eventuales incidencias en el servicio por incumplimientos del contratista generan habitualmente un impacto negativo en la opinión pública, lo que provoca que en numerosas ocasiones la Administración titular del servicio se vea en la necesidad de adoptar soluciones de urgencia que implican un gran desembolso económico, a la espera de la solución legal, que suele demorarse en el tiempo ${ }^{22}$. Estas situaciones se han incrementado en los últimos tiempos, conjugándose las dificultades económicas de ciertos contratistas con la imposibilidad por parte de la Administración de desembolsar las cantidades que requiere una correcta y pronta solución de este tipo de incidencias.

k) Una incorrecta interpretación de los principios de riesgo y ventura del contratista y del mantenimiento del equilibrio económico del contrato han provocado lo que se ha dado en llamar "privatización de los beneficios y socialización de las pérdidas" en materia de servicios públicos. Las cláusulas contenidas en los pliegos del contrato han generalizado un sistema por el cual los beneficios excesivos nunca revierten a la Administración titular del servicio público, mientras que casi sin excepción se aseguran límites mínimos de ingresos, que son compensados por la Administración en caso de no alcanzarse por la empresa prestadora del servicio. De este modo, la buena marcha del servicio desde el punto de vista económico no afecta positivamente a la Administración titular, mientras que la ausencia de los beneficios esperados sí le afecta, en este caso negativamente.

1) La reciente crisis económica ha multiplicado una situación que hasta estos momentos era anecdótica dentro del panorama administrativo español: los impagos a los contratistas del servicio público por parte de la Administración. Esta situación ha llevado a su vez, en situaciones extremas, a la suspensión del servicio por parte de los encargados contractualmente de su prestación, con el correspondiente perjuicio para los ciudadanos. Un ejemplo característico son las suspensiones del suministro eléctrico por falta de pago por parte de la Administración. Se trata de situaciones ciertamente excepcionales, pero que generan una gran alarma social y efectos perniciosos sobre la confianza de los ciudadanos en las instituciones públicas.

m) Por último, y en relación con el último de los modos de gestión indirecta de los servicios públicos previstos en el TRLCSP, la sociedad de economía mixta, se

${ }^{22}$ Ad exemplum, el rescate por parte del Ayuntamiento de Jerez de la Frontera (Cádiz) del servicio de transporte público urbano por incumplimientos reiterados del contratista, y que ha sido avalado recientemente por el Juzgado de lo Contencioso-Administrativo $\mathrm{n}^{\circ} 1$ de este municipio. 
observa cómo de forma más o menos habitual, el socio de la Administración no es elegido por sus virtudes empresariales sino por su cercanía o afinidad con dicha institución, lo que inevitablemente va a redundar en perjuicio de la eficacia y eficiencia del servicio público.

La tesis defendida en este trabajo consiste en afirmar que la vigente normativa sobre contratación pública, complementada por el parecer de la Junta Consultiva de Contratación Administrativa del Estado y la Jurisprudencia de los Tribunales, prevé mecanismos suficientes para solucionar todos estos problemas y garantizar la necesaria eficacia en la actuación administrativa exigida por el artículo 103.1 CE, minimizando las corruptelas habituales en esta materia. Debido a la extensión del mismo, únicamente se tratarán los asuntos que son considerados nucleares en materia de gestión indirecta de servicios públicos, dejando el resto de cuestiones problemáticas para ulteriores estudios.

\section{MEGANISMOS PARA UNA CORREGTA VALORACIÓN DEL SERVICIO PÚBLICO. LA REVISIÓN DE PRECIOS Y LA PRÓRROGA DEL CONTRATO}

Los artículos 87 y 88 TRLCSP establecen reglas y pautas generales para establecer el importe de los contratos de gestión de servicios públicos. En el primero de ellos se establecen reglas comunes a todos los contratos, señalando que el precio - retribución pagada al contratista- deberá ser cierto, esto es, determinado y adecuado para el efectivo cumplimiento del contrato mediante la correcta estimación de su importe, atendiendo al precio general del mercado. Señala la Junta Consultiva de Contratación Administrativa del Estado que "la claridad del texto y su mandato no requiere mayor explicación, con la excepción de que coordinando con el artículo [88] en la determinación del precio, el órgano de contratación ha de llevar a cabo una correcta estimación de su importe" ${ }^{\text {"23 }}$. El citado artículo 88 TRLCSP establece las reglas generales para la estimación del valor del contrato - coste global para la Administración-, estando éste determinado por el importe total, sin incluir el Impuesto sobre el Valor Añadido, pagadero según las estimaciones del órgano de contratación, debiendo tenerse en cuenta cualquier forma de opción eventual, prórrogas del mismo ${ }^{24}$ o primas y pagos a los candidatos o licitadores. Como en el caso anterior, dicha estimación deberá hacerse teniendo en cuenta los precios habituales en el mercado al momento del envío del anuncio de licitación o inicio del proce-

\footnotetext{
${ }^{23}$ Informe JCCA n ${ }^{\circ}$ 44/12, de 7 de mayo de 2013.

${ }^{24}$ En relación al cálculo del valor de un contrato que incluye la posibilidad de prórroga vid. el Informe JCGA n ${ }^{\circ}$ 44/12, de 7 de mayo de 2013.
} 
dimiento de adjudicación. Recuerda el Tribunal de Cuentas que "[] a correcta determinación del presupuesto base de licitación es una de las exigencias claves de la contratación pública y ha de ajustarse al valor de mercado, como establece[n] [...] [los artículos 87 y 88 TRLCSP] en relación con el artículo 66.1 del Reglamento de Contratos (RGLCAP) concerniente a las declaraciones económicas que habrán de contenerse en los Piegos de Cláusulas Administrativas" 25 . Una correcta valoración del contrato resulta fundamental para evitar los sobreprecios en la contratación, que son la principal rémora de la eficacia administrativa, pero también inciden en otros aspectos fundamentales a la ahora de configurar el contrato de gestión de servicio público: contratación menor u ordinaria, órgano de contratación o posibilidad de recursos especiales, entre otros ${ }^{26}$.

El problema está en que el TRLCSP no establece fórmulas específicas para calcular el valor de los contratos de gestión de servicios públicos más allá de las reglas generales de los artículos 87 y 88 . El TRLCSP únicamente prevé reglas precisas de valoración en caso de resolución del contrato en los supuestos previstos en el artículo 286 letras b), c) y d) -rescate del servicio, supresión del servicio por razones de interés público e imposibilidad de la explotación del servicio como consecuencia de acuerdos adoptados por la Administración con posterioridad al contrato-, obligando a la Administración a indemnizar al contratista por los daños y perjuicios irrogados, incluyendo el lucro cesante y las obras e instalaciones que deban revertir a aquéllas en función de su estado y tiempo que restase para la misma, atendiendo a los resultados de la explotación en el último quinquenio. Advierte la Junta Consultiva de Contratación Administrativa que tales criterios - resultados de la explotación u obras e instalaciones construidas por el contratista- no pueden aplicarse a efectos de determinar el valor del contrato en su momento inicial por la sencilla razón de que aún no existen en el momento de su adjudicación ${ }^{27}$. Considera igualmente que ni se puede acudir a normas sectoriales para determinar el valor de estos contratos ${ }^{28}$, ni son necesarias normas específicas para cada una de las modalidades del mismo - concesión, gestión interesada, concierto o sociedad de economía mixta-, ni, y esto es lo más importante, son necesarias otras normas específicas para la correcta valoración de estos

${ }^{25}$ Informe del Tribunal de Cuentas no 1.034, Global del Sector Público Autonómico, ejercicios 2010 y 2011; 29 de mayo de 2014, pág. 360.

${ }^{26}$ Para el resto de modalidades contractuales, la consideración o no de contrato armonizado.

${ }^{27}$ Informe $n^{\circ} 49 / 10$, de 28 de octubre de 2011.

${ }^{28}$ Como, por ejemplo, las reglas de valoración previstas en el artículo 13.3 del Texto Refundido de la Ley del Impuesto de Transmisiones Patrimoniales y Actos Jurídicos Documentados, tal y como se propone desde el Excmo. Ayuntamiento de Almussafes (Valencia) en el Informe n ${ }^{\circ}$ 49/10, de 28 de octubre de 2011. 
contratos, bastando las reglas generales contenidas en los artículos 87 y 88 TRLCSP, en el entendimiento de que "el órgano de contratación dispone de información suficiente para poder valorar el importe del contrato [...]", pudiendo "[...] procederse [por éste] [...] a valorar, mediante la correspondiente estimación, los diversos factores que se integran en el mismo".

Pero ¿cómo se plasman estas estimaciones en el expediente de contratación? Tales consideraciones deberán estar recogidas en un documento fundamental, que necesariamente debe figurar en el expediente de contratación: el estudio económico-administrativo del servicio (art. 183.1 RGLCAP), que forma parte del proyecto de explotación de todos aquellos servicios que proyecten ser explotados con unidad e independencia funcional, y que deberán ser incorporados por el órgano de contratación al citado expediente con anterioridad a su aprobación ${ }^{29}$. Por tal razón, el órgano de contratación debe plasmar en el expediente todos aquellos datos que permitan una correcta valoración del servicio, tanto en el mencionado estudio como en las cláusulas administrativas particulares aplicables al mismo, tal y como dispone el artículo 67.4 RGLCAP. Será, por lo tanto, la Administración contratante la que determine en cada caso cuál es el importe del contrato y no los licitadores los que singularmente propongan el mismo a aquélla. Tal y como señala la Junta Consultiva de Contratación Administrativa del Estado, "cabe concluir que el órgano de contratación dispone de información suficiente para poder valorar el importe del contrato que expresará como presupuesto base de licitación"30. Lamentablemente, el Tribunal de Cuentas ha hecho notar recientemente que, en relación al estudio económico-financiero, éste "[...] presenta debilidades [en todo el ámbito autonómico, si bien con mayor intensidad en la Comunidad Autónoma de Aragón] y en algunos casos no se incluye en el [Pliego de Cláusulas Administrativas Particulares] el valor estimado del contrato como precisa [el TRLCSP] [...]"31.

Únicamente existe una excepción a esta determinación previa del importe del contrato, justificada por la naturaleza de las prestaciones objeto del mismo. El artículo 87.5 TRLCSP permite a la Administración celebrar contratos con precios provisionales cuando éstos se adjudiquen utilizando el procedimiento negociado o el diálogo competitivo y se ponga de manifiesto - expresamente- que la ejecución del contrato debe comenzar antes de que resulte posible determinar el

${ }^{29}$ Así lo recuerda sucintamente la JCCA, ad exemplum, en su Informe $\mathrm{n}^{\circ}$ 27/93, de 22 de diciembre de 1993 (Consideración 3 ${ }^{\mathrm{a}}$ ). También, de forma expresa, en el Informe n ${ }^{\circ}$ 49/10, de 28 de octubre de 2011.

${ }^{30}$ Informe JCGA n ${ }^{\circ} 44 / 12$, de 7 de mayo de 2013, pág. 3 in fine.

${ }^{31}$ Informe del Tribunal de Cuentas $n^{\circ} 1.034$... Op.cit., pág. 360. 
precio debido a la complejidad de las prestaciones o se trate de una técnica novedosa, así como en los casos en los que no existiese información sobre los costes de prestaciones análogas - por estar fuera del mercado- o sobre los elementos técnicos y contables que permitan negociar con precisión un precio cierto. Sin embargo, aún en estos casos, en los que el precio se determinará a posteriori en función de costes en los que realmente incurra el contratista y el beneficio previamente acordado, deberá fijarse obligatoriamente en las condiciones de contratación un precio máximo, además de las siguientes previsiones: "a) El procedimiento para determinar el precio definitivo, con referencia a los costes efectivos y a la fórmula de cálculo del beneficio; b) Las reglas contables que el adjudicatario deberá aplicar para determinar el coste de las prestaciones; y c) Los controles documentales y sobre el proceso de producción que el adjudicador podrá efectuar sobre los elementos técnicos y contables del coste de producción".

Por lo que se refiere al canon o participación que eventualmente satisfará el adjudicatario del contrato a la Administración, y que conforme al artículo 67.4 RGLCAP debe estar previsto expresamente en el pliego de cláusulas administrativas particulares, se considera que forma parte esencial del proyecto de explotación del servicio público (art. 133.1 TRLCSP) y, por lo tanto, debe quedar reflejado obligatoriamente en el estudio económico-administrativo, como elemento fundamental para la determinación del valor del mismo. En cualquier caso, la Junta Consultiva de Contratación Administrativa del Estado niega la legalidad de que la empresa adjudicataria abone dicho canon, de una sola vez, al inicio del contrato, al entender que "[...] el pretendido anticipo de tal remuneración no se contrasta con las remuneraciones que se prevén existan en el contrato como consecuencia de la percepción por el contratista de las tarifas que los usuarios abonarán a la empresa concesionaria de la gestión del servicio público" ${ }^{32}$; o que éste se abone en especie ${ }^{33}$. En relación con este canon, la crisis económica ha generado una situación desconocida hasta la fecha: la licitación de contratos de gestión de servicio públicos sin canon a favor de la Administración como consecuencia de su escasa rentabilidad (v.gr. ciertas instalaciones deportivas, como las piscinas municipales). Esta posibilidad, permitida por la Ley, debe ser utilizada como último recurso y siempre que se acredite fehacientemente la necesidad de prescindir de esta remuneración como único mecanismo para la participación del sector privado, evitando situaciones de cesión gratuita de dominio público ${ }^{34}$.

${ }^{32}$ Informe 67/04, de 11 de marzo de 2005. Sobre esta posibilidad, señala además la JCGA que "[s] i pudiera admitirse debería necesariamente figurar en el pliego de cláusulas administrativas particulares con el necesario detalle de cuantos aspectos de todo orden se relaciones con tal posibilidad".

${ }^{33} \mathrm{Al}$ menos en el ámbito local por prohibición expresa del artículo 165.3 TRLHL. Vid. Informe JCGA n ${ }^{\circ}$ 23/94, de 19 de diciembre de 1994.

${ }^{34}$ Sobre este supuesto excepcional vid. el Informe JCGA 25/2012, de 20 de noviembre. 
En relación con la necesidad de una correcta valoración del contrato está la posibilidad, amparada por la legislación, de revisar el precio del mismo durante su vigencia, y que tradicionalmente ha dado lugar a irregularidades en esta materia ${ }^{35}$. Como ha recordado la Junta Consultiva de Contratación Administrativa del Estado, para que dicha revisión pueda tener lugar resulta imprescindible que los pliegos de cláusulas administrativas particulares o el propio contrato detallen la fórmula o el sistema de revisión aplicable (art. 89.3 TRLCSP) ${ }^{36}$, pudiendo excluirse de plano esta posibilidad mediante resolución motivada del órgano de contratación plasmada en los mismos documentos (art. 89.2 TRLCSP). El legislador concede libertad a la Administración para elaborar las fórmulas que estime convenientes ${ }^{37}$ pero limitadas a la ponderación sobre el precio del contrato del coste de los materiales básicos y de la energía ${ }^{38}$ incorporados al proceso de generación de las prestaciones objeto del mismo, sin que puedan tenerse en cuenta - como regla general- el coste de la mano de obra ${ }^{39}$, los costes financieros ${ }^{40}$, los

${ }^{35} \mathrm{El}$ Tribunal de Cuentas ha advertido en diversas ocasiones sobre esta circunstancia. Por todos, vid. su Informe n 955 de Fiscalización de la contratación celebrada durante el ejercicio 2009 por las entidades estatales que, de acuerdo con la Ley de Contratos del Sector Público, tienen la consideración de Administraciones Públicas; 20 de diciembre de 2012, pág. 233.

36 Vid. ad exemplum los Informes $\mathrm{n}^{\circ}$ 15/02, de 13 de junio de 2002; y 59/03, de 7 de junio de 2004.

${ }^{37}$ Siempre a salvo de la posibilidad de remitirse a los índices o fórmulas oficiales aprobadas por el Consejo de Ministros (art. 90 TRLCSP).

38 Cuyos índices de precios serán aprobados por la Comisión Delegada del Gobierno para Asuntos Económicos con una periodicidad mensual y publicados en el B.O.E., pudiendo ser únicos para todo el territorio nacional o sectorizados geográficamente (art. 91.4 TRLCSP).

${ }^{39} \mathrm{Ni}$ siquiera como consecuencia de aumentos salariales pactados en convenios colectivos. Por todos, el Informe JCCA n ${ }^{\circ}$ 25/06, de 20 de junio de 2006, que sin embargo parece abrir la puerta a su inclusión dentro de otros indicadores no específicos, al afirmar que "[...] las variaciones de precios por incremento de los costes de personal, sólo pueden tener reflejo en el precio del contrato a través de las correspondientes fórmulas de revisión de precios en los que se haya tomado en consideración tal componente".

${ }^{40}$ Con respecto a estos dos elementos, dispone el art. 90.2 TRLCSP que "[c]uando por circunstancias excepcionales la evolución de los costes de mano de obra o financieros acaecida en un periodo experimente desviaciones al alza que puedan reputarse como impredecibles en el momento de la adjudicación del contrato, el Consejo de Ministros o el órgano competente de las Comunidades Autónomas podrá autorizar, con carácter transitorio, la introducción de factores correctores de esta desviación para su consideración en la revisión del precio, sin que, en ningún caso, puedan superar el 80 por 100 de la desviación efectivamente producida. Se considerará que concurren las circunstancias a que se refiere el párrafo anterior cuando la evolución del deflactor del Producto Interior Bruto oficialmente determinado por el Instituto Nacional de Estadística supere en 5 puntos porcentuales las previsiones macroeconómicas oficiales efectivas en el momento de la adjudicación o el tipo de interés de las letras del Tesoro supere en cinco puntos porcentuales al último disponible en el momento de la adjudicación del contrato. Los pliegos de cláusulas administrativas particulares podrán incluir las referencias a las previsiones macroeconómicas y tipo de interés existentes en el momento de la licitación". 
gastos generales o de estructura ni el beneficio industrial (art. 91.1 TRLCSP). La determinación de los materiales que son considerados como básicos a efectos de su inclusión en las fórmulas de revisión de precios se hace por norma reglamentaria, señalándose además que los indicadores o reglas de determinación de cada uno de los índices que intervienen en las fórmulas de revisión de precios serán establecidos por Orden del Ministro de Economía y Hacienda, a propuesta del Comité Superior de Precios de Contratos del Estado (art. 91.5 TRLCSP). A ello debe añadirse que las fórmulas de revisión de precios serán invariables durante la vigencia del contrato (art. 91.4 TRLCSP) ${ }^{41}$. Como recuerda la Junta Consultiva de Contratación del Estado ${ }^{42}$, "[i] ncluida en el pliego una cláusula de revisión de precios [...] resulta obligado su cumplimiento, como obligación de la Administración de pagar el precio revisado y derecho del contratista de percibirlo, sin que [durante su vigencia] [...] pueda cuestionarse [...] la inadecuación de la fórmula de revisión pactada pues tal cuestión, como es lógico [,] debió plantearse y ser resuelta en el momento anterior de elaboración y aprobación del pliego con arreglo al cual se invocó la licitación del contrato".

Teniendo en cuenta todas estas reglas y limitaciones, la revisión de precios debe considerarse una posibilidad circunscrita a los supuestos permitidos expresamente por el legislador ${ }^{43}$, sin que pueda ampliarse a circunstancias no recogidas en los pliegos contractuales y mucho menos alterar las fórmulas de revisión de precios durante la vigencia del mismo para amparar circunstancias no previstas en aquéllos. Extremando el celo respecto a estas fórmulas de revisión de precios, la Junta Consultiva de Contratación Administrativa del Estado advierte sobre la posibilidad de aplicar aquéllas únicamente durante la eventual prórroga del contrato, estando vedada durante el plazo original del mismo. En estos casos, tales revisiones únicamente estarán permitidas cuando las fórmulas aplicables estén previstas en los pliegos de modo que no quede duda de la forma en que se podrán aplicar en caso de prórroga ${ }^{44}$. En caso contrario, deberá aplicarse el citado artículo 91.4 TRLCSP: las fórmulas de revisión de precios serán invariables durante la vigencia del mismo.

41 Vid. Informe JCCA 38/00, de 21 de diciembre de 2000.

42 Informe $n^{\circ}$ 29/00, de 30 de octubre de 2000.

${ }^{43} \mathrm{Al}$ contrario de lo que interpretó la JCCA - Informe n ${ }^{\circ}$ 68/04, de 11 de marzo de 2005- en relación con el artículo 162 de la antigua Ley de Contratos de las Administraciones Públicas: en los contratos de gestión de servicios públicos las previsiones contractuales recogidas en sus pliegos prevalecían sobre las previsiones en materia de revisión de precios, al señalar este precepto que "el contratista tiene derecho a las prestaciones económicas previstas en el contrato y a la revisión de las mismas, en su caso, en los términos que el propio contrato establezca". La regulación actual de esta cuestión no propicia una interpretación semejante.

${ }^{44}$ En relación a esta posibilidad, aconseja la JCCA que "[...] para supuestos similares se aclare la aplicación de la cláusula de revisión de precios, y a se establezca para todo el periodo de duración del contrato, ya exclusi- 
La única posibilidad de acoger circunstancias no previstas en los pliegos contractuales en orden a la modificación del precio pactado se encuentra en un mecanismo distinto, y que no es otro que el necesario mantenimiento del equilibrio económico del contrato. La Junta Consultiva de Contratación Administrativa del Estado ha admitido expresamente esta posibilidad amparándose en los artículos 126.2 b), 127.2.2.1 y 128.3.2.1 del Reglamento de Servicios de las Corporaciones Locales (RSCL), siempre que se justifiquen debidamente los incrementos experimentados en los elementos determinantes del incremento de costes ${ }^{45}$. Esta técnica está prevista expresamente en la normativa sectorial para el contrato de gestión de servicios públicos (arts. 282 TRLCSP), y a sus requisitos y exigencias deberá estarse si el concesionario pretende la modificación del precio del contrato por esta vía. Sobre este mecanismo, la propia Junta Consultiva de Contratación Administrativa del Estado aclara que "tiene [...] que actuar al margen y con independencia de la revisión de precios y se articula [...] a través de mecanismos que por circunstancias extraordinarias e imprevisibles [generadas por la propia actuación de la Administración o causadas por fuerza mayor], permiten una alteración de la prestación del contratista y no de la Administración que por las mismas circunstancias podrá ejercitar el "ius variandi ${ }^{\prime \prime} 46$.

Por último, el TRLCSP limita con carácter general la posibilidad de revisar los precios a la ejecución efectiva de un veinte por ciento de su importe y al transcurso de al menos un año desde su formalización ${ }^{47}$, si bien en el caso de los contratos de gestión de servicios públicos se elimina el primero de los requisitos, habida cuenta de las grandes magnitudes que suelen caracterizar a estos con$\operatorname{tratos}^{48}$.

vamente para las prórrogas como se hace en el supuesto presente. Con ello se evitarian las dudas que ahora se plantean a los órganos de contratación y se volvería el principio de transparencia frente a los licitadores que podrían ponderar en sus ofertas el elemento de revisión de precios". Informe n 57/04, de 12 de noviembre de 2004.

${ }^{45}$ Informe ${ }^{\circ}$ 59/03, de 7 de junio de 2004, Consideración $n^{\circ} 2$ in fine.

${ }^{46}$ Sobre esta materia vid., entre otros, FERNÁNDEZ GARCÍA, J. F., "Equilibrio económico y revisión de precios en los contratos administrativos", en la Revista Española de Derecho Administrativo, n ${ }^{\circ}$ 163, 2014, págs. 145 a 180; o VVAA, "Servicios públicos de la Administración local. Abastecimiento de aguas: gestión indirecta y equilibrio económico de los contratos", en Consultor de los ayuntamientos y de los juzgados: Revista técnica especializada en administración local y justicia municipal, $\mathrm{n}^{\circ}$ 12, 2010, págs. 1851 a 1853.

${ }^{47}$ Requisitos acumulativos, no alternativos. Informe JCGA n ${ }^{\circ}$ 17/97, de 14 de julio de 1997.

48 Así lo consideró la JCGA en sus informes n ${ }^{\circ}$ 27/93, de 22 de diciembre de 1993; 48/00, de 21 de diciembre de 2000; y 68/04, de 11 de marzo de 2005. En este último -anterior a la aceptación de este criterio en el texto legal- advierte, en relación a tal cuestión, que "[ $\mathrm{t}]$ ratándose de contratos de gestión de servicios públicos se debe sostener que, de los dos límites o umbrales exentos de revisión, solo debe jugar el plazo dado que, por las especial naturaleza de estos contratos, con larga proyección en el tiempo, el de la cuan- 
Muy relacionada con la valoración de los contratos y el precio a satisfacer al contratista está su duración y eventuales prórrogas. La duración de los contratos públicos, y en concreto de los contratos de gestión de servicios públicos, tiene una gran importancia ya que durante su vigencia parcelas de la actividad económica quedan excluidas del tráfico mercantil, bloqueando la concurrencia del sector privado, siendo ésta la razón por la que se suprimió la posibilidad de que estos contratos tuviesen carácter perpetuo/indefinido o pseudo-indefinido (al establecerse plazos injustificadamente extensos). Ya se ha comentado cómo el cálculo de los plazos máximos de duración de esta modalidad contractual se hace sobre una estimación genérica del tiempo necesario para amortizar las inversiones acometidas y garantizar un porcentaje razonable de beneficio industrial ${ }^{49}$. El órgano de contratación deberá justificar en el estudio económico-administrativo el plazo de duración del contrato en función de tales parámetros, sin necesidad de agotar los plazos máximos fijados por la Ley. La fijación del plazo es, por tanto, una potestad discrecional de la administración, que como tal debe ser convenientemente motivada y susceptible de control por la jurisdicción contenciosa ${ }^{50}$. Ajustar la duración del contrato a las necesidades reales del mismo acrecienta la concurrencia real del sector privado en las parcelas de actividad pública gestionadas de forma indirecta, mejorando la eficacia administrativa al revisarse las condiciones del mismo en periodos de tiempo más cortos. Una mayor movilidad temporal de los contratistas redunda en beneficio del ciudadano y de la libertad empresarial, ya que aumenta las posibilidades de renovación de las condiciones de contratación y su adaptación a las circunstancias del momento, además de propiciar la concurrencia competitiva en lapsos menores de tiempo.

tía viene intimamente unido al del plazo y subsumido en el mismo, de tal modo que, si se aceptara la existencia de dos umbrales, el plazo actuaría en una doble vertiente como umbral estricto de plazo (un año) y como umbral de cuantía determinado a su vez por el plazo (en el presente caso cuatro años) con lo que se observa lo ilógico de tal postura que, en consecuencia, no debe ser mantenida, si se tiene en cuenta, sobre todo, que en el contrato de gestión de servicios públicos juega como principio fundamental el del mantenimiento del equilibrio económico financiero del contrato que no podría ser mantenido si excluyese la revisión de precios durante un periodo superior a un año y fijando el umbral exento de revisión en función de la cuantía y la duración del contrato.".

${ }^{49}$ Recuérdese que este plazo es de 25 años con carácter general, 50 años si comprende la ejecución de ejecución de obras y explotación del servicio público (60 años si se tratase de un mercado o lonja central mayorista de productos alimentarios gestionados por una sociedad de economía mixta municipal), y 10 años si se trata de un servicio público de naturaleza sanitario (y no comprenda la ejecución de obras y explotación del servicio) (art. 278 TRLCSP).

${ }^{50}$ Sobre esta importante materia vid. AGUDO GONZÁLEZ, J., "El tiempo en las concesiones de servicio público. Continuidad en la prestación del servicio y potestas variandi versus libre concurrencia”, en Revista General de Derecho Administrativo, n 26, 2011. 
Pero los plazos contractuales pueden, además, ser objeto de una o varias prórrogas - dentro de los límites máximos fijados para cada modalidad contractual-, siempre que "sus características permanezcan inalterables durante el período de duración de éstas y que la concurrencia para su adjudicación haya sido realizada teniendo en cuenta la duración máxima del contrato, incluidos los periodos de prórroga" (art. 23.2 TRLCSP), es decir, que el plazo de duración únicamente podrá ser prorrogado si se encuentra previsto en los pliegos o el propio contrato, siendo parte del contenido mínimo obligatorio de éstos (art. $26.1 \mathrm{~g}$ ) TRLCSP). La prórroga será declarada en todo caso por el órgano de contratación, sin que resulten admisibles las prórrogas tácitas, y será obligatoria para el contratista, salvo que se pacte expresamente su voluntariedad (art. 23.2 párrafo segundo TRLCSP). La importancia de este mecanismo es tal que su utilización deberá ser comunicada por el órgano de contratación a la Junta Consultiva de Contratación Administrativa del Estado o a los Registros de Contratos autonómicos (art. 30 TRLCSP), además de al Registro de Contratos del Sector Público estatal (art. 333.3 TRLCSP). Este mecanismo ha sido utilizado tradicionalmente para ampliar la duración del contrato en fraude de ley, modificando sus características de forma que pueden considerarse como nuevos contratos cuyo término final se va posponiendo una y otra vez mediante ampliaciones sistemáticas de su plazo, manteniendo al margen a los posibles competidores que pretenden ofertar sus servicios a la Administración. Tal ha sido la magnitud del problema que recientemente, la Comisión Mixta para las Relaciones con el Tribunal de Cuentas ha acordado dirigirse al Gobierno del Estado para instar a sus Entidades Públicas a fin de que éstas mejoren "[...] los estudios previos y elaboración de los proyectos, aportando mayor precisión en la determinación de las necesidades a cubrix, con el fin de evitar las modificaciones, ampliaciones de plazo, retrasos y obras complementarias no justificadas", debiendo adoptar "[...] las medidas para que la ejecución del contrato se ajuste a los plazos pactados y, en su caso, las correspondientes prórrogas" 51.

Con respecto a los contratos de gestión de servicios públicos, el legislador reproduce las reglas generales de este mecanismo: obligatoriedad de fijación en el pliego de cláusulas administrativas particulares e imposibilidad de que su aplicación sobrepase los plazos máximos fijados para cada materia (art. 278 TRLCSP), a lo que añade la posibilidad de utilizar este mecanismo como instrumento para restablecer el equilibrio económico del contrato ante determinadas circunstancias, con el límite del diez por ciento de su duración inicial y los plazos máximos fijados para esta modalidad contractual (art. 282.5 TRLCSP). Deberá prestarse

${ }^{51}$ Resolución de 8 de abril de 2014, aprobada por la Comisión Mixta para las Relaciones con el Tribunal de Cuentas, en relación con el Informe de fiscalización de la contratación celebrada durante los ejercicios 2010 y 2011 por las Entidades Estatales que, de acuerdo con la Ley de Contratos del Sector Público, tienen la consideración de Administraciones Públicas. 
especial atención, por tanto, a que el cálculo del plazo global del contrato -al que se acaba de hacer referencia- se haga incluyendo las eventuales prórrogas, que la ampliación de los plazos se realice con base en prórrogas previstas expresamente en el contrato y que éstas no se aprovechen para modificar las características del contrato, alterando su naturaleza, lo que en la práctica puede llegar a suponer una nueva adjudicación en vulneración de los principios de publicidad y concurrencia $^{52}$. Como recuerda la Junta Consultiva de Contratación Administrativa del Estado 53 , "[...] el contrato prorrogado no es un nuevo contrato, sino el contrato primitivo que [...] sigue produciendo sus efectos durante el periodo de prórroga", por lo que durante este nuevo plazo "[...] el contrato ha de ajustarse a las condiciones iniciales bajo las que se celebró, fundamentalmente en materia de precio", debiendo estar especialmente atentos a este momento para evitar modificaciones al alza del precio del contrato o alteraciones de las fórmulas de revisión del mismo.

Por último, existe la posibilidad de prorrogar la duración original del contrato con el objetivo de restablecer su equilibrio económico, pero siempre respetando los límites y requisitos fijados por la normativa de contratación y las cautelas expuestas $^{54}$. En cualquier caso, debe tenerse en cuenta que la Junta Consultiva de Contratación Administrativa del Estado es contraria a utilizar la prórroga no prevista en el contrato como mecanismo para mantener el equilibrio económico de los contratos de gestión de servicios públicos cuando este desequilibrio tenga su origen en inversiones realizadas por el concesionario y que no han podido ser amortizadas al finalizar su plazo de vigencia, ni para realizar nuevas obras aunque éstas resulten imprescindibles para garantizar de forma urgente la calidad del servicio público ${ }^{55}$.

${ }^{52}$ Un supuesto de hecho de esta naturaleza fue analizado por la JCCA en su Informe n ${ }^{\circ}$ 9/99, de 30 de junio de 1999, en el que se examina la posibilidad de que, con ocasión de la ampliación del plazo de un contrato de gestión de servicio público de abastecimiento de agua potable, el concesionario construya una estación de tratamiento de agua potable (que revertiría al municipio al extinguirse la relación contractual). Considera la Junta Consultiva que la construcción de esta obra supone una "modificación del objeto del contrato que implica una alteración sustancial de las bases y criterios a los que responde la adjudicación del mismo [...], y a que ello supone un obstáculo a los principios de concurrencia y buena fe que deben presidir la contratación de las Administraciones Públicas, habida cuenta que los licitadores distintos del adjudicatario podian haber modificado sus proposiciones si hubieran sido conocedores de la modificación que posteriormente se produce".

${ }^{53}$ Informe 52/00, de 5 de marzo de 2001.

${ }^{54}$ Sobre esta posibilidad vid. GALLEGO CÓRCOLES, I., "La ampliación del plazo concesional como fórmula del restablecimiento del equilibrio económico del contrato", en Contratación administrativa práctica: revista de la contratación administrativa y de los contratistas, $\mathrm{n}^{\circ} 118,2012$, págs. 54 a 61.

${ }^{55}$ En el supuesto analizado en el Informe 7/06, de 24 de marzo de 2006, el concesionario de un contrato de gestión de servicio público de abastecimiento de agua potable realiza una serie de in- 


\section{ESTÁNDARES DE CALIDAD EN LA PRESTACIÓN DEL SERVICIO Y TÉGNICAS PARA SU ASEGURAMIENTO}

Las condiciones de prestación del servicio, que determinan el nivel de calidad del mismo, son un componente esencial tanto de las cláusulas administrativas particulares como de las prescripciones técnicas del contrato (art. 133.1 TRLCSP). En relación con estas últimas, el artículo 116.1 TRLCSP señala que "[e]l órgano de contratación aprobará con anterioridad a la autorización del gasto o conjuntamente con ella, y siempre antes de la licitación del contrato, o de no existir ésta, antes de su adjudicación, los pliegos y documentos que contengan las prescripciones técnicas particulares que hayan de regir la realización de la prestación y definan sus calidades, de conformidad con los requisitos que para cada contrato establece la presente Ley", por lo que, como ocurre con el precio del contrato, los estándares de calidad exigidos al prestador del servicio quedan prefijados en el propio expediente administrativo, sin que puedan ser propuestos singularmente por los participantes en el proceso de licitación.

Lo primero que llama la atención al analizar la normativa de contratación pública es la considerable atención que presta en materia de calidad en relación con los contratos de suministro y servicios ${ }^{56}$, en contraste con la prestada en el caso de contratos de gestión de servicios públicos, prácticamente nula más allá de las determinaciones generales para todos los tipos contractuales. En ambos casos, uno de los componentes esenciales para la acreditación de la solvencia técnica de los empresarios candidatos será la "[i]ndicación del personal técnico o unidades técnicas, integradas o no en la empresa, de los que se disponga para la ejecución del contrato, especialmente los encargados del control de calidad", además del control realizado por "[...] la entidad del sector público contratante o, en su nombre, por un organismo oficial competente del Estado en el cual el empresario está establecido, siempre que medie acuerdo de dicho organismo, cuando los productos a suministrar sean complejos o cuando, excepcionalmente, deban responder

\footnotetext{
versiones para adaptar y mantener las infraestructuras que no pudieron ser amortizadas en el plazo original de vigencia del contrato, además de alertar sobre la necesidad de realizar una serie de obras para garantizar la calidad del servicio ofrecido. Por ambas razones solicita la ampliación del plazo original, denegándose por la JCGA al considerar que [...] la prórroga del contrato no prevista en el mismo no puede ser utilizada para mantener el equilibrio económico financiero de la concesión ni para realizar obras que, aunque sean necesarias, deben tener su encaje en un nuevo contrato a celebrar, dado el inminente vencimiento del actualmente en vigor". Tampoco acepta que el órgano de contratación utilice el ius variandi para esta finalidad, ya que recuerda que esta potestad sólo puede utilizarse ante circunstancias nuevas o causas imprevistas, ni tampoco recurrir a la modificación consensuada, que en ningún caso puede alterar sustancialmente el objeto original del contrato.

56 También en relación al contrato de obras, si bien principalmente enfocado al resultado y no a la prestación en sí (vid. art. 123.1 c) TRLCSP)
} 
a un fin particular ${ }^{57}$. Este control versará sobre la capacidad de producción del empresario y, si fuera necesario, sobre los medios de estudio e investigación con que cuenta, así como sobre las medidas empleadas para controlar la calidad", así como la aportación de "[c]ertificados expedidos por los institutos o servicios oficiales encargados del control de calidad, de competencia reconocida, que acrediten la conformidad de productos perfectamente detallada mediante referencias a determinadas especificaciones o normas" (art. 77 TRLCSP). A todo esto se le suma, en el caso de los contratos de servicios, la "[d] escripción de las instalaciones técnicas, de las medidas empleadas por el empresario para garantizar la calidad y de los medios de estudio e investigación de la empresa" 58 . Incluso, en los contratos de concesión de obra pública, el legislador prevé la posibilidad - que no obligación- de que el órgano de contratación incluya en los pliegos de condiciones mecanismos para la medición de la calidad del servicio, así como la posibilidad de otorgar ventajas o establecer penalizaciones económicas al contratista en función de la misma (art. 247.5 TRLCSP).

Tampoco le es aplicable a los contratos de servicio público la obligación genérica establecida para todos los contratos sujetos a regulación armonizada consistente en hacer referencia, por parte del órgano de contratación, a los sistemas de aseguramiento de la calidad basados en la normativa europea sectorial, certificados por organismos conformes a las normas europeas de certificación, cuando dicho órgano exija la presentación de certificados exigidos por organismos independientes que acrediten que el empresario cumple determinadas normas de garantía de calidad (art. 80.1 TRLCSP). En relación a las funciones previstas para el Registro de Contratos del Sector Público, el artículo 333 TRLCSP únicamente alude a la calidad al referirse a los proveedores, por lo que parece circunscribirse exclusivamente al contrato de suministro. Y otro tanto ocurre al relacionarse las estipulaciones obligatorias del contrato de colaboración entre el sector público y el sector privado, que únicamente se refiere a la calidad de las prestaciones de los servicios, de las obras y de los suministros (art. 136 c) TRLCSP) ${ }^{59}$. Pero en este último caso, y a pesar de que la intención del legislador, tras el análisis sistemático del articulado del TRLCSP, parece circunscribirse a los contra-

57 En el caso de contratos de servicios, cuando se trate de un servicio o trabajo complejos o, excepcionalmente, deban responder a un fin especial (art. 78.1 d) TRLCSP).

58 Este interés por la calidad del producto suministrado es tal que el legislador otorga a la Administración la facultad de "[...] facultad de inspeccionar y de ser informada del proceso de fabricación o elaboración del producto que haya de ser entregado como consecuencia del contrato, pudiendo ordenar o realizar por sí misma análisis, ensayos y pruebas de los materiales que se vayan a emplear, establecer sistemas de control de calidad y dictar cuantas disposiciones estime oportunas para el estricto cumplimiento de lo convenido." (art. 295 TRLCSP).

${ }^{59}$ En el mismo sentido, vid. art. 67 RGLCAP. 
tos de servicios, nada obsta para entender el concepto servicios en su acepción más amplia, referida a esta modalidad contractual, pero también a los contratos de gestión de servicios públicos. Resulta difícil de entender el olvido del legislador en materia de técnicas de aseguramiento de la calidad de los servicios públicos gestionados indirectamente más allá de las previsiones genéricas para todas las modalidades contractuales. Pareciera que la considera una cuestión secundaria o que, en todo caso, queda al buen hacer de cada una de las administraciones contratantes y sus facultades de policía y control.

A pesar de esta falta de atención específica por parte del legislador, la calidad de las prestaciones forma parte indubitable de las condiciones de prestación del servicio, y su incumplimiento tiene consecuencias jurídicas para el contratista. Estas consecuencias tienen una doble naturaleza e intensidad: penalizaciones sobre el precio a percibir ${ }^{60}$ y, para los casos más graves de incumplimiento, la suspensión de la relación contractual mediante la intervención del mismo ${ }^{61} \mathrm{o}$, en casos extremos, la resolución del contrato mediante el rescate ${ }^{62}$. Como advierte el artículo 279 TRLCSP, "[e]l contratista está obligado a organizar y prestar el servicio con estricta sujeción a las características establecidas en el contrato y dentro de los plazos señalados en el mismo, y, en su caso, a la ejecución de las obras conforme al proyecto aprobado por el órgano de contratación", por lo que la pieza clave para garantizar a los ciudadanos unos niveles adecuados de calidad en la prestación del servicio público es una adecuada determinación de tales parámetros en los pliegos contractuales y, como garantía de los mismos, la utilización de los mecanismos que la Ley proporciona a los poderes públicos en caso de incumplimiento, en virtud de la potestad de policía que éstos ostentan y a la que se hará referencia ad infra. En tal sentido, el Tribunal de Cuentas ha recomendado recientemente a la Administración General del Estado -siendo extensivo para el resto de Administraciones públicas- que realice "[...] un mayor seguimiento de la ejecución de los contratos y del cumplimiento de los plazos, haciendo efectivas las garantías en caso de incumplimiento y, en su caso, la imposición de penalidades", habida cuenta de las irregularidades detectadas en este ámbito ${ }^{63}$. Sin

60 Siempre que, como exige el artículo 87.4 TRLCSP, se determinen con precisión los supuestos en los que se producirán estas variaciones en el precio original y las reglas para su determinación.

61 Recuérdese que el artículo 285 TRLCSP prevé que " $[$ s 7 i del incumplimiento por parte del contratista se derivase perturbación grave y no reparable por otros medios en el servicio público y la Administración no decidiese la resolución del contrato, podrá acordar la intervención del mismo hasta que aquélla desaparezca. En todo caso, el contratista deberá abonar a la Administración los daños y perjuicios que efectivamente le haya irrogado".

62 Prevista expresamente en los artículos 286 y 287.2 TRLCSP.

63 Informe del Tribunal de Cuental $n^{\circ} 1.011$, de Fiscalización de la contratación celebrada durante los ejercicios 2010 y 2011 por las entidades estatales que, de acuerdo con la Ley de Contratos del Sector Público, tienen la consideración de Administraciones Públicas; 23 de diciembre de 2013, pág. 289. 
embargo, debe tenerse en cuenta que el establecimiento de penalidades en caso de incumplimiento es una facultad potestativa del órgano de contratación ${ }^{64}$, por lo que su inclusión en los pliegos contractuales no es obligatoria. En cualquier caso, debería justificarse la no inclusión de dichos mecanismos - algo que no se hace a día de hoy- para facilitar la fiscalización de tales decisiones del órgano de contratación. La no inclusión de penalidades en caso de incumplimiento afecta negativamente al mandato constitucional de eficacia administrativa, por lo que el legislador debería reconsiderar su postura al respecto.

Recuerda la Junta Consultiva de Contratación Administrativa del Estado ${ }^{65}$ que las consecuencias del incumplimiento del contratista deben ser examinadas desde una doble perspectiva: la normativa sobre contratación pública y las disposiciones específicas del servicio público en cuanto no se opongan a ella, conformada por las normas autonómicas -si las hubiese-y, en todo caso, la Ley 7/1985, de 2 de abril, reguladora de las Bases de Régimen Local; el Real Decreto 781/1986, de 18 de abril, que aprueba el Texto Refundido de las disposiciones legales vigentes en materia de Régimen Local; y el Reglamento de Servicio de las Corporaciones Locales de 17 de junio de 1955. Existen, por tanto, dos fuentes de regulación de la actuación del contratista. Una primera de origen legal, compuesta por el conjunto normativo referenciado por la Junta Consultiva; y otra de origen contractual, y conformada por el contenido de los pliegos suscritos por las partes del contrato. Todas éstas obligan al contratista y de su adecuado cumplimiento dependerá que el servicio proporcionado a los ciudadanos mantenga o no unos niveles adecuados de calidad. Por ello, a pesar del silencio de la normativa sobre contratación y del contrato mismo, es posible acudir a la normativa sectorial sobre servicios públicos en busca de mecanismos frente al incumplimiento de los estándares de calidad, si bien hay que advertir que como regla general éstos son muy limitados en la práctica.

Como lamenta GIRALDES GUTIÉRREZ ${ }^{66}$, la calidad del servicio prestado por el contratista ha sido una de las primeras víctimas de la crisis económica. Dos son los fenómenos que para este autor están repercutiendo negativamente en dicha calidad: por un lado, la importancia creciente que se concede en las licitaciones a las bajas económicas presentadas por las empresas candidatas; y, por otro

${ }^{64} \mathrm{El}$ artículo 87.4 TRLCSP utiliza la expresión "podrán incluir" en relación a dichas penalidades.

${ }^{65}$ Informe no 61/96, de 18 de diciembre de 1996.

${ }^{66}$ GIRALDES GUTIÉRREZ, L. S., "La introducción de una encuesta de calidad asociada a la ejecución del contrato como elemento para aumentar la eficiencia en la utilización de los recursos públicos asociados a la contratación", Observatorio de Contratación Pública, publicación online de 5 de noviembre de 2012 . 
lado, la mayor competencia y la circunstancia anterior conminan a las empresas a presentar ofertas con presupuestos muy ajustados, en los que la calidad del servicio se resiente en muchas ocasiones. En el marco del Libro Verde sobre la modernización de la politica de contratación de la Unión Europea: Hacia un mercado europeo de la contratación pública más eficiente ${ }^{67}$, propone la elaboración de encuestas de calidad asociadas a la ejecución del contrato, incluidas en los Pliegos de Prescripciones Técnicas - para que queden integradas dentro del vínculo contractual- y que tendrán como finalidad la implicación de los usuarios en la apreciación de los estándares de calidad, aparejando ciertas penalidades -leves- al incumplimiento de los mismos por parte del contratista - reflejados tanto en el resultado de las encuestas como por la misma ausencia de éstas ${ }^{-68}$. Al preverse la realización de encuestas periódicas a los usuarios y la identificación de unos objetivos mínimos de calidad en el contenido obligacional, su inobservancia por parte del contratista tendrá la consideración de incumplimiento contractual, con las consecuencias analizadas supra. Pero no sólo se van a aparejar consecuencias negativas a los resultados de las encuestas, recordando la posibilidad de elaborar un sistema de primas o bonificaciones vinculadas a la consecución - reflejada en las encuestas- de los objetivos de calidad propuestos. A todo lo expuesto sería conveniente añadir la precaución de externalizar la realización de dichas encuestas para garantizar su autenticidad, recogiendo en el clausulado del contrato la obligación de que las mismas sean encargadas obligatoriamente a terceros independientes y de prestigio reconocido.

En definitiva, ante la escasa atención del legislador a una cuestión de tanta importancia como es la calidad del servicio público prestado a los ciudadanos, deben reclamarse unos estándares transparentes - previstos en el clausulado contractual de forma clara y precisa-, unos mecanismos que permitan aparejar de forma automática determinadas penalizaciones ante el incumplimiento de dichos estándares y, fundamentalmente, una voluntad por parte de la administración de fiscalizar la correcta ejecución del contrato, con técnicas como la expuesta en el párrafo anterior y las que serán analizadas en su epígrafe específico.

${ }^{67}$ Comisión Europea, Bruselas, 27 de enero de 2001, COM(2011) 15 final. Señala esta publicación que "[...] las autoridades públicas pueden introducir [a la hora de externalizar (sic) servicios públicos] requisitos relativos, en particular, a la calidad, la exhaustividad y la continuidad del servicio de que se trate, así como referentes a la implicación y la participación de los usuarios en prestación y la evaluación del servicio o para asegurar que los prestadores se hayan familiarizado con el contexto local [...]", pág. 51.

${ }^{68}$ Entiende este autor que "[c] on el sistema propuesto se satisfacen colateralmente otras necesidades administrativas, tales como, [...] la disminución de los gastos de personal del órgano de contratación (capitulo I) dedicado a verificar la correcta ejecución del contrato, ya que parte de sus labores de control se puede entender delegada en los usuarios, quienes manifestarán su opinión sobre el servicio contratado, resaltando los puntos débiles del mismo al órgano de contratación a efectos de control y corrección". 


\section{LA EQUIDISTRIBUCIÓN DEL RIESGO DE EXPLOTACIÓN ENTRE EL CONTRATISTA Y LA ADMINISTRAGIÓN. NUE- VAS FÓRMULAS PARA LA SOCIALIZAGIÓN DE LOS BE- NEFICIOS}

El TRLCSP no predetermina el porcentaje del precio que debe ser satisfecho al contratista en concepto de beneficio industrial, dejándolo a la libre apreciación del órgano de contratación ${ }^{69}$. En otras modalidades contractuales, como el contrato de obras, el RGLCAP estableció, al regular los presupuestos de ejecución material y base de licitación, porcentajes fijos tanto en concepto de gastos - del trece al diecisiete por ciento ${ }^{70}-$ como de beneficio industrial - seis por ciento- $^{-}$, incluyendo una serie de elementos que podían ser considerados gastos generales (gastos de empresa, gastos financieros, cargas fiscales, tasas administrativas, etc) ${ }^{71}$. Tales previsiones únicamente serán aplicables a los contratos de gestión de servicios públicos cuando sea necesaria la realización de obras para su establecimiento $^{72}$. Por tal razón, con carácter general tanto el beneficio a obtener por el contratista como los diferentes elementos que formarán parte de los gastos o costes de explotación serán determinados en cada caso concreto por el órgano de contratación, atendiendo a los precios generales del mercado y los usos habituales en la economía española. La fijación de un beneficio razonable para la empresa contratista resulta fundamental para evitar sobrecostes en la gestión pública y salvaguardar el principio de eficacia en su actuación ${ }^{73}$.

La normativa sobre contratación pública exige que tanto en los pliegos de cláusulas administrativas particulares (art. 67.4 e) RGLCAP) como en el documento de formalización del contrato (art. 71.5 c) RGLCAP) se recoja obligatoriamente el beneficio mínimo que corresponda a alguna de las partes (si no se ha optado por recoger el canon o participación a satisfacer a la administración por el contratista). Nada se señala sobre el beneficio máximo de las partes. Esta falta de

69 Únicamente lo hace para supuestos de desistimiento o suspensión del contrato por parte de la Administración, yendo en estos casos del 3 al $10 \%$ del precio de los trabajos dejados de realizar (arts. 300 y 309 TRLCSP).

${ }^{70}$ Fijado con carácter general en el 13 \% por la Orden FOM/1824/2013, de 30 de septiembre.

71 Sobre estos gastos y su consideración a la hora del cálculo del beneficio industrial vid. el Informe $\mathrm{JCCA} \mathrm{n}^{\circ}$ 50/08, de 2 de diciembre de 2008.

${ }^{72}$ Artículo 183.2 RGLCAP.

73 Sobre estas y otras cuestiones relacionadas con la contratación pública vid. el interesante $E U$ Anti-corruption Report, Informe de la Comisión al Consejo y al Parlamento Europeo, de 3 de febrero de 2014, COM(2014) 38 final, con un anexo específico para España (Anexo 9). 
previsión sobre los límites máximos de beneficios genera situaciones admisibles desde el punto de vista jurídico pero difícilmente comprensibles desde el económico o social: cuando el beneficio empresarial baja por debajo de determinados umbrales la Administración pública se hace cargo de este déficit, pero cuando aquél es mucho mayor del esperado los rendimientos extraordinarios no revierten en los ciudadanos. Es el fenómeno de la socialización de las pérdidas y privatización de los beneficios al que se ha hecho referencia en epígrafes anteriores. Aunque en contratos de una cierta entidad es habitual establecer umbrales mínimos y máximos de beneficios para el contratista (siendo muy comunes en los contratos de concesión de obra pública), no es una obligación legal, por lo que no están previstos en muchos contratos de gestión de servicios públicos. Se trata por tanto de una situación que debiera ser materia de reflexión por parte del legislador, garantizando el equilibrio económico de las relaciones público-privadas más allá de la técnica del enriquecimiento injusto, de dudosa utilidad en circunstancias como las descritas.

En relación con la racionalización del beneficio industrial, merecen especial atención las nuevas fórmulas para el cálculo de la retribución del contratista utilizadas por varias Administraciones públicas, que se alejan del mecanismo tradicional consistente en la determinación de un precio "fijo" en el momento de suscribir el acuerdo contractual. Estas fórmulas establecen mecanismos mediante los cuales la retribución del contratista consistirá en un porcentaje de los rendimientos obtenidos (por ejemplo, sobre la recaudación lograda - $\mathrm{O}$ su incremento- por la Administración en la gestión indirecta de un servicio público) o del ahorro generado por aquél. Sobre estos sistemas, recuerda el Consejo de Estado ${ }^{74}$ que precio cierto "no es precio fijo, pues con referencia a aquél lo que ha dispuesto la legislación [...] es la certeza de la concurrencia del precio, no de sus contingencias". Para la Junta Consultiva de Contratación Administrativa del Estado, "el principio de precio cierto admite un precio sujeto a variaciones, aunque determinable en todo caso" 75 . La Junta Consultiva admite la legalidad de la primera de las fórmulas retributivas planteadas siempre que se respete el artículo 87.4 TRLCSP, que admite que los contratos, cuando su naturaleza y objeto lo permitan, podrán incluir cláusulas de variación de precios en función del cumplimiento de determinados objetivos de plazos o de rendimiento. En este caso, la cuantía del precio dependerá del cumplimiento del objetivo de incrementar la recaudación de un determinado servicio, objetivo que para la Junta Consultiva queda "perfectamente definido". Este precepto exige también que se determinen con precisión los supuestos en los que se producirá dicha variación de precios y las reglas para su determinación, extremos que también se

\footnotetext{
${ }^{74}$ Dictamen de 4 de marzo de 1993.

${ }^{75}$ Informe $n^{\circ} 52 / 09$, de 26 de febrero de 2010.
} 
cumplen pues "[e]l supuesto es, una vez más, el incremento en la recaudación y la regla para la determinación del montante del precio es tan claro como aplicar un porcentaje sobre ese incremento". Esta fórmula de determinación del precio es admisible al ser considerado un "precio determinable que cumple con el principio de precio cierto", por lo que resulta admisible retribuir al contratista única y exclusivamente con un porcentaje sobre el importe de la recaudación obtenida - $\mathrm{O}$ su incremento- en la gestión del servicio público ${ }^{76}$.

En cuanto al segundo de los mecanismos de retribución del contratista -en el que el precio, total o parcial, consistirá en un porcentaje sobre el ahorro generado a la Administración-, la Junta Consultiva de Contratación Administrativa del Estado admite ${ }^{77}$ esta modalidad de pago siempre que dicho ahorro resulte "verificable, medible o estimable", entendiendo que en tales casos "el precio, si bien no es fijo, resulta determinable si se introducen los correspondientes parámetros que permitan cuantificar su variación en base a [sic] los ahorros de consumo energético verificados". Incluso, considera la Junta Consultiva que se dan las circunstancias para la aplicación del régimen excepcional de precios provisionales previstos en el artículo 87.5 TRLCSP y analizados ad supra, encajando en el supuesto de hecho previsto en este precepto: "cuando, tras la tramitación de un procedimiento negociado o de diálogo competitivo, se ponga de manifiesto que la ejecución del contrato debe comenzar antes de que la determinación del precio sea posible por la complejidad de las prestaciones o la necesidad de utilizar una técnica nueva, o que no existe información sobre los costes de prestaciones análogas y sobre los elementos técnicos o contables que permitan negociar con precisión un precio cierto", fijándose éste conforme a las reglas previstas en el propio precepto. Aunque la consulta que origina este pronunciamiento de la Junta Consultiva se refiere a la posibilidad de que las empresas de servicios energéticos sean remuneradas, total o parcialmente, con un porcentaje sobre el ahorro que se genere como consecuencia de la implantación de proyectos de mejora de la eficiencia energética ${ }^{78}$, aquélla reconoce expresamente que esta posibilidad es aplicable, con carácter general, a la contratación de to-

76 En el supuesto de hecho analizado por la Junta Consultiva, la retribución al contratista consistía en un porcentaje sobre el importe efectivamente cobrado (principal, intereses y sanciones) como consecuencia de la gestión conjunta de determinados expedientes administrativos, cuyas funciones son repartidas entre la Administración y el contratista conforme a lo establecido en el artículo 9.2 EBEP.

${ }^{77}$ Informe $n^{\circ} 59 / 2011$, de 1 de marzo de 2012.

78 Tal y como prevé expresamente el propio Real Decreto-Ley 6/2010, de 9 de abril, de medidas para el impulso de la recuperación económica y el empleo, definiendo éstas como "[...] aquella persona fisica o jurídica que pueda proporcionar servicios energéticos, [...] en las instalaciones o locales de un usuario y afronte cierto grado de riesgo económico al hacerlo."; y en relación a su remuneración, exige que "[...] el pago por los servicios prestados se base, y a sea en parte o totalmente, en la obtención de ahorros de energía por introducción de mejoras de la eficiencia energética y en el cumplimiento de los demás requisitos de rendimiento convenidos." (art. 19). 
do el sector público, incluyendo -aunque guarde silencio a este respecto- los contratos de gestión de servicios públicos.

Ambos sistemas de remuneración del contratista contribuyen a lograr una mayor eficacia en la gestión pública que la fijación, en el momento de licitar el contrato, de un precio cierto de carácter inamovible, ya que sendos mecanismos fomentan que la empresa alcance - e, incluso, mejore- los objetivos establecidos en el contrato, haciendo depender el beneficio empresarial de los resultados obtenidos en la gestión del servicio público y vinculando de forma directa éxito empresarial y beneficio social.

\section{SUPERVISIÓN Y GONTROL DE LA EJEGUCIÓN DEL CON- TRATO: LA AUDITORÍA COMO MEGANISMO FUNDA- MENTAL}

Como se ha expuesto ad supra, el artículo 279 TRLCSP recuerda al contratista su obligación de organizar y prestar el servicio público encomendado con estricta sujeción a los parámetros y plazos fijados en el contrato, incluyendo las obras previstas en el proyecto aprobado por el órgano de contratación. Para asegurar el cumplimiento de tales obligaciones, el legislador advierte de que "[e]n todo caso, la Administración conservará los poderes de policía necesarios para asegurar la buena marcha de los servicios de que se trate", reafirmando el carácter irrenunciable de la potestad de vigilancia y control del cumplimiento del contenido contractual por parte de las Administraciones públicas. Además, precisa el artículo 280 TRLCSP -obligaciones del contratista- que la habilitación hecha a éste para dictar las instrucciones que considere oportunas en orden a la buena marcha del servicio se entenderán, en todo caso, sin perjuicio de los poderes de policía atribuidos a la Administración.

Estas son las únicas referencias que hace la Ley de contratos a la potestad de vigilancia y control de las Administraciones públicas sobre el correcto cumplimiento de las obligaciones contractuales por parte del adjudicatario del contrato en relación con la modalidad de gestión de servicios públicos. Estas previsiones genéricas contrastan con las previstas en la misma norma en relación a otras modalidades contractuales, como las relativas al contrato de colaboración entre el sector público y el privado, entre cuyo clausulado obligatorio figuran las "[f]órmulas de control por la Administración de la ejecución del contrato, especialmente respecto a los objetivos de rendimiento [...]" (art. $136 \mathrm{~g}$ ) TRLCSP); o al contrato de concesión de obra pública, que enumera las prerrogativas y derechos de la Administración, incluyendo la capacidad para "[v]igilar y controlar el cumplimiento de las obligaciones del concesionario, a cuyo efecto podrá inspeccionar el servicio, sus obras, instalaciones y locales, así 
como la documentación, relacionados con el objeto de la concesión" (art. 249.1 f) TRLCSP). En puridad, estas previsiones no atribuyen mayores potestades a la Administración en materia de vigilancia y control del cumplimiento de los contratos con respecto a la previsión genérica del artículo 279.2 TRLCSP. Sin embargo, no hubiera estado de más que la Ley de contratos incluyese, para los contratos de gestión de servicios públicos, la obligación de explicitar en el texto del mismo los concretos mecanismos de vigilancia y control de las prestaciones contractuales que son asumidos por la Administración pública, a modo de como hace el citado artículo 136 g) TRLCSP. En cualquier caso, el artículo 94.2 RGLCAP establece la obligación genérica, para todas las modalidades contractuales, de que "[1]os pliegos de cláusulas administrativas, generales y particulares, conten[gan] las declaraciones precisas sobre el modo de ejercer esta potestad administrativa". De tal forma que siempre será una obligación para la Administración plasmar en la documentación contractual las técnicas y mecanismos concretos que serán utilizados para controlar el correcto cumplimiento de las obligaciones asumidas por el contratista, aunque en la práctica tal obligación se descuide con mayor frecuencia de la deseada. A la vista de las irregularidades que usualmente se producen en la prestación de servicios públicos gestionados de forma indirecta ${ }^{79}$, resulta esencial que la Administración idee y plasme en el contrato, para su general conocimiento y obligatoriedad ab initio, los concretos mecanismos de control que aplicará durante la vigencia del mismo. El propio Tribunal de Cuentas echa en falta dicha concreción, al advertir sobre la omisión generalizada, en los pliegos contractuales, de "[d]eclaraciones sobre el modo concreto en que el órgano de contratación supervisará la actuación del contratista en el desarrollo de la ejecución del contrato (artículo 94 del Reglamento General de la Ley de Contratos de las Administraciones Públicas)" ${ }^{\prime 80}$.

En el ámbito local, el RSCL atribuye a la Corporación local la potestad para fiscalizar la gestión del concesionario, sus obras, instalaciones y locales, así como la documentación relacionada con el objeto de la concesión, pudiendo dictar las ordenes necesarias para mantener o restablecer el servicio en las condiciones pactadas contractualmente (art. $\left.127.12^{\mathrm{a}}\right)$. Esta previsión, en principio limitada a los servicios públicos locales gestionados a través de la modalidad de concesión, puede servir de modelo para fijar, con carácter general, la amplitud y profundidad de la actividad administrativa de control del contratista, no sólo en la modalidad concesional, sino en el resto de modalidades ofrecidas por la Ley de Contratos.

\footnotetext{
${ }^{79}$ Sobre esta preocupante situación advierte GIMENO FELIÚ, J. Mª., "La necesaria y urgente política de reformas frente a la corrupción", en Observatorio de Contratación Pública, publicación online de 4 de febrero de 2013.

${ }^{80}$ Informe del Tribunal de Cuentas n ${ }^{\circ} 1.011$... Op.cit, pág. 285.
} 
Aunque ésta encomienda tal actividad de control a los propios órganos de la Administración, que la ejerce a través de sus servicios técnicos, nada obsta, en virtud del citado artículo 25 TRLCSP, a que se recoja en los pliegos contractuales la externalización de una parte de dicha actividad, encomendándola al sector privado. De este modo, la Administración, que en ningún caso puede renunciar a la potestad de vigilancia y control, recaba el auxilio de un tercero para garantizar la neutralidad e independencia de esta actividad. La auditoría externa de la ejecución de los contratos de gestión de servicios públicos se revela como un instrumento idóneo para ${ }^{81}$, por un lado, evaluar el grado de cumplimiento de las estipulaciones recogidas en el contrato, permitiendo a la Administración poner en funcionamiento los mecanismos frente a incumplimientos contractuales -en materia, por ejemplo, de estándares de calidad del servicio-; y, por otro lado, determinar el coste de prestación de los servicios para calcular el beneficio empresarial, evitando enriquecimientos injustos o rupturas del equilibrio económico del contrato $^{82}$, como se verá a continuación. Asociar automáticamente un sistema de penalizaciones al contratista con los resultados de la auditoría externa debería ser el reto a cumplir por los gestores públicos, respetando en cualquier caso el procedimiento establecido al efecto en la Ley de Contratos.

En tal sentido, tanta importancia como la vigilancia y el control de la ejecución de un contrato adjudicado tiene el control de costes y precios de tales contratos. Como advierte GÓMEZ GUZMÁN ${ }^{83}$, existen dos causas que impiden que el órgano de contratación tenga certeza sobre la razonabilidad del precio de los contratos: en primer lugar la asimetría en materia de información económica que poseen contratistas y Administraciones públicas; y en segundo lugar, la dificultad de promover la concurrencia en determinadas licitaciones. Para estos casos se propone que un tercero ajeno al órgano de contratación y al contratista analice los datos relativos al contrato y determine la exactitud de los datos sobre coste y precio -incluyendo el beneficio industrial- presentados por el adjudicatario. Su virtualidad estriba en aumentar la confianza de la Administración en relación a los costes y precios presentados por los contratistas, logrando una mayor

${ }^{81}$ MARTÍNEZ FUENTES, A. L., "El control de las concesiones y servicios prestados de forma externalizada", en II Congreso Nacional de Auditoría del Sector Público, Sevilla, 2006.

${ }^{82}$ A modo del sistema NODECOS (Normas sobre los criterios a emplear en el cálculo de costes en determinados contratos de suministros, consultoría y servicios del Ministerio de Defensa). Para este autor, "[h] a de evitarse la incoherencia de que entre los criterios objetivos de adjudicación del concurso se establezca el [porcentaje] de beneficio que el concesionario prevé obtener y no se incluyan mecanismos de control sobre si el beneficio real obtenido se adecua al reflejado en la oferta del adjudicatario". Ídem, pág. 6.

83 GÓMEZ GUZMÁN, J. C., "Auditoría de costes y precios de contratos públicos", Observatorio de Contratación Pública, publicación online de 17 de marzo de 2014. 
eficiencia en la contratación pública. Además, la información proporcionada por el auditor puede incluso alertar a la Administración sobre posibles debilidades financieras del candidato que puedan poner en peligro la adecuada ejecución del contrato adjudicado, aumentando el tiempo de respuesta de la Administración ante este tipo de contingencias. Con base en estos datos, la Administración puede determinar de forma fehaciente el precio a pagar por cada uno de los contratos adjudicados ${ }^{84}$. Se trata de una técnica que sirve para fijar el precio del contrato y, por ende, el beneficio del contratista, por lo que bien podría incluirse en el epígrafe anterior. Pero también tiene cabida en el presente epígrafe pues se trata de un mecanismo de control de la ejecución del contrato, pues es en esta fase en la que la auditoría tiene lugar.

Pero para que este mecanismo pueda ser aplicado es necesario acabar con la costumbre - si bien cada vez menor- de establecer un precio fijo para los contratos públicos. Como se ha puesto de manifiesto en estas páginas, el precio cierto exigido por el artículo 87 TRLCSP no exige un precio fijo, sino uno determinable en virtud de las fórmulas establecidas en el propio contrato. A mayor abundamiento, este artículo admite expresamente en su número 2 que el precio del contrato pueda formularse "en términos de precios unitarios referidos a los diferentes componentes de la prestación", entre los que pueden estar los costes realmente incurridos por el contratista. Su admisibilidad, por tanto, queda fuera de toda duda ${ }^{85}$, máxime si se trata de un contrato con precios provisionales, en los que esta posibilidad está incluso prevista por la propia Ley de Contratos para su concreción.

${ }^{84}$ Como señala este autor, "[p]odría decirse que la auditoría de contratos es un proceso de acumular y evaluar evidencia mediante un examen sistemático realizado por un profesional independiente, respecto del sujeto auditado (el contratista), y cuyo alcance son los estados de costes por él presentados y los registros y transacciones que los soportan, todos los cuáles están relacionados con los costes de las ofertas económicas de las licitaciones y los incurridos de la ejecución de los contratos, y que son sometidos por el contratista a su examen para determinar su grado de adherencia a principios de general aceptación en materia de cálculo, clasificación, asignación y afectación de costes de los contratos públicos y a los requerimientos establecidos en cláusulas contractuales o en disposiciones legales; también, el alcance abarca a las politicas de gestión establecidas por la dirección de la empresa contratista y a sus sistemas de control interno, para determinar el riesgo de auditoría y, consecuentemente, la extensión y profundidad de los trabajos que el auditor de contratos deba efectuar en las auditorías de ofertas y en las de costes incurridos. Por último, el auditor de contratos comunica los resultados al órgano gestor contratante para que determine el precio final y efectúe el pago del contrato.”. Ídem, pág. 1.

85 Precisa este autor que "[p] ara aplicar definitivamente la auditoría de contratos sólo faltaría que, en los pliegos de cláusulas administrativas del contrato (PCAP), se especificara: (1) la norma de costes aplicable, (2) los costes prohibidos o no permitidos del contrato, (3) los techos máximos o límites de impugnación de ciertos costes, y (4) la cláusula de sometimiento a la auditoría de contratos del coste incurido, con el carácter de obligación contractual esencial.". Ídem, pág. 3. 
Los beneficios más importantes ${ }^{86}$ de esta técnica son, dejando a un lado la mejora general de la eficiencia en la asignación de recursos por parte de la Administración, la posibilidad de vaciar de contenido las complejas fórmulas de revisión de precios - que en ocasiones disparan éstos en relación al presupuesto original-, habida cuenta de que éstos serán determinados durante la vigencia del contrato con base en los costes efectivamente incurridos por el contratista en función de los precios del mercado existentes en cada momento. Además, el hecho de que los precios se determinen en función de los costes incurridos por el contratista permite a la Administración establecer incentivos a su ahorro, de forma que el beneficio para ambas partes aumente en función del ahorro efectivamente logrado.

La reciente Directiva 2014/24/UE sobre contratación pública recoge la importancia de los costes a la hora de adjudicar el contrato, señalando que para determinar cuál es la oferta económicamente más ventajosa el órgano de contratación "[...] no deberá basarse únicamente en criterios no relacionados con los costes. Por ello, los criterios cualitativos deben ir acompañados de un criterio relacionado con los costes, el cual, a elección del poder adjudicador, podría ser el precio o un planteamiento basado en la rentabilidad, como el coste del ciclo de vida"87. Más aún, advierte esta Directiva que los poderes adjudicadores podrán determinar cuál es la oferta económicamente más ventajosa y el coste más bajo -en aquellos casos en los que se tengan en cuenta otros parámetros además del precio- mediante un planteamiento basado en el coste del ciclo de vida $(C C V)^{88}$, entendido éste como la diferencia entre la inversión necesaria y los ingresos que genera -rentabilidad, en este caso, social-, concepto que incluye todos los costes del servicio desde su concepción hasta su desaparición ${ }^{89}$. Se plantea, además, la viabilidad de establecer un método común para el cálculo del ciclo de vida en todo el territorio europeo. La Directiva adelanta el momento de análisis de costes a un momento anterior al planteado supra, ya que en este caso aquéllos son usados para adjudicar el contrato y no como mecanismo para determinar el precio de un contrato en ejecución. Pues bien, estos nuevos criterios de adjudicación deberán ser aplicados de manera objetiva y no discriminadora por los órganos de contratación, jugando un papel esencial la auditoría de costes,

86 Otros beneficios en Ídem, págs. 4 y 5.

${ }^{87}$ Directiva 2014/24/CE, del Parlamento Europeo y del Consejo, de 26 de febrero de 2014, sobre contratación pública y por la que se deroga la Directiva 2004/18/CE, Considerando $92^{\circ}$.

88 Ídem, Considerando $96^{\circ}$.

${ }^{89}$ Entre tales costes están los costes de adquisición, utilización, consumo de energía y otros recursos, mantenimiento, externalidades, medioambientales y final de vida (incluyendo costes de recogida y reciclado). Ídem, artículo 68. 
que permitirán determinar la propuesta más eficiente desde el punto de vista económico, social y medioambiental, además del concreto precio a pagar en cada uno de ellos ${ }^{90}$.

\section{REFLEXIÓN FINAL}

A pesar de los problemas prácticos que la gestión indirecta de los servicios públicos puede ocasionar y del creciente rechazo social que generan en determinadas materias, el Ordenamiento Jurídico provee - al menos en los elementos analizados- de los instrumentos suficientes para su correcta gestión, posibilitando la utilización de una multiplicidad de mecanismos que aumentan la fiabilidad del sistema, tal y como ha demostrado la Junta Consultiva de Contratación Administrativa del Estado en sus pronunciamientos. Si bien es cierto que cualquier procedimiento es mejorable, como se ha puesto de manifiesto a lo largo de estas páginas, siendo deseable la adopción, por parte del legislador, de las modificaciones propuestas, entre otras planteadas por la doctrina. En cualquier caso, el objetivo de este breve estudio era mostrar que no son necesarias grandes modificaciones del régimen jurídico de la contratación pública, que éste ofrece al gestor público los mecanismos necesarios para una correcta licitación y ejecución del contrato de gestión de servicios públicos, y que depende de la voluntad del órgano de contratación la construcción de un vínculo público-privado lo más satisfactorio posible para el interés público. Quizá el legislador debiera reducir la discrecionalidad de la Administración en ciertos aspectos especialmente sensibles, pero lo cierto es que ésta dispone de todos los mecanismos necesarios para que la gestión indirecta de los servicios públicos sea respetuosa con el principio de eficacia administrativa y satisfactoria para la ciudadanía.

\footnotetext{
90 Así lo considera GÓMEZ GUZMÁN en "Directiva 2014/24/CE y auditoría de contratos", Observatorio de Contratación Pública, publicación online de 28 de abril de 2014; al señalar que "[...] la viabilidad de establecer un método común sobre el cálculo del coste del ciclo de vida, ya sea en los costes estimados de las ofertas como en el coste incurrido, queda resuelto por la auditoría de costes y precios de contratos públicos (o auditoría de contratos), al menos en lo que se refiere a los costes tradicionales. Dicha metodología puede abarcar desde la propia fase conceptual y de desarrollo del producto, pasando por la fase de fabricación y continuando durante todo el periodo de vida en servicio, hasta los costes de su eliminación o desactivación. Por otro lado, las técnicas para determinar la razonabilidad de la estimación de los costes de las ofertas pueden basarse en relaciones paramétricas verificables por técnicas de la auditoría de contratos. Luego, durante el periodo de ejecución del proyecto, puesta en servicio y eliminación, deben comprobarse los costes y el beneficio reclamado por los operadores económicos adjudicatarios para efectuar el pago del precio de los contratos, mediante pagos parciales y liquidación final, previa aplicación de una auditoría de costes incurridos y conforme a sus resultados.".
} 


\section{BIBLIOGRAFÍA}

AGUDO GONZÁLEZ, J., "El tiempo en las concesiones de servicio público. Continuidad en la prestación del servicio y potestas variandi versus libre concurrencia”, en Revista General de Derecho Administrativo, nº 26, 2011.

COMISIÓN EUROPEA, Libro Verde sobre los Servicios de Interés General, Bruselas, 21 de mayo de 2003, Bruselas, COM (2003) 270 final, págs. 15 y 16.

- EU Anti-corruption Report, Informe al Consejo y al Parlamento Europeo, Bruselas, de 3 de febrero de 2014, $\operatorname{COM}(2014) 38$ final.

- Libro Verde sobre la modernización de la política de contratación de la Unión Europea: Hacia un mercado europeo de la contratación pública más eficiente, Bruselas, 27 de enero de 2001, $\operatorname{COM}(2011) 15$ final.

CONSEJO DE ESTADO, Dictamen de 4 de marzo de 1993.

FERNÁNDEZ GARCÍA, J. F., "Equilibrio económico y revisión de precios en los contratos administrativos", en la Revista Española de Derecho Administrativo, $\mathrm{n}^{\circ}$ 163, 2014, págs. 145 y ss.

FLORES DOMÍNGUEZ, L. E., "Aspectos jurídicos del precio del agua. Especial referencia a la empresa metropolitana de aguas de Sevilla (EMASESA)", en la Revista Andaluza de Administración Pública, Instituto Andaluz de Administración Pública, no 87, septiembre-diciembre, 2013, Sevilla, págs. 303 y ss.

GALLEGO CÓRCOLES, I., "La ampliación del plazo concesional como fórmula del restablecimiento del equilibrio económico del contrato", en Contratación administrativa práctica: revista de la contratación administrativa y de los contratistas, $\mathrm{n}^{\circ}$ 118, 2012 , págs. 54 y ss.

GIMENO FELIÚ, J. Mª ., "La necesaria y urgente política de reformas frente a la corrupción", en Observatorio de Contratación Pública, publicación online de 4 de febrero de 2013.

GIRALDES GUTIÉRREZ, L. S., "La introducción de una encuesta de calidad asociada a la ejecución del contrato como elemento para aumentar la eficiencia en la utilización de los recursos públicos asociados a la contratación", $O b$ servatorio de Contratación Pública, publicación online de 5 de noviembre de 2012. 
GÓMEZ GUZMAN en "Directiva 2014/24/CE y auditoría de contratos", Observatorio de Contratación Pública, publicación online de 28 de abril de 2014.

- "Auditoría de costes y precios de contratos públicos", Observatorio de Contratación Pública, publicación online de 17 de marzo de 2014.

\section{JUNTA GONSULTIVA DE CONTRATACIÓN ADMINISTRATIVA} DEL ESTADO, diversos informes.

LAGUNA DE PAZ, J. G., "Regulación, externalización de actividades administrativas y autorregulación", en la Revista de Administración Pública, n 185, 2011, págs. 89 y ss.

MARTÍNEZ FUENTES, A. L., "El control de las concesiones y servicios prestados de forma externalizada", en II Congreso Nacional de Auditoría del Sector Público, Sevilla, 2006.

MARTÍNEZ PALLARÉS, P.L., "Particularidades del contrato de gestión de servicios públicos. En particular su regulación en el ámbito local", en Cuadernos de Derecho Local, Fundación Democracia y Gobierno Local, nº 2, 2003, págs. 147 y ss.

MORENO MOLINA, J. A. y PLEITE GUADAMILLAS, F., La nueva Ley de Contratos del Sector público. Estudio sistemático, 3a edición, La Ley, 2011.

NAVARRO RODRÍGUEZ, P., "La externalización de la función de control en materia de energías renovables, ahorro y eficiencia energéticas en Andalucía", en Actualidad Administrativa, $\mathrm{n}^{\circ}$ 4, 2012.

PONCE SOLÉ, J., El derecho y la (ir)reversibilidad limitada de los derecho sociales de los ciudadanos. Las líneas rojas constitucionales a los recortes y la sostenibilidad social, Instituto Nacional de Administración Pública, Colección Monografias, 2013, Madrid.

RODRÍGUEZ ESCANGIANO, S., "Los despidos objetivos en las administraciones públicas, rescate de contratas y concesiones y supresión de entidades o estructuras administrativas", en La reforma del sector público local, Castillo Blanco, F. (Dir.) et al, Instituto García Oviedo, Universidad de Sevilla, 2014, págs. 369 y ss.

TRIBUNAL DE CUENTAS, Informe $\mathrm{n}^{\circ} 1.011$, de Fiscalización de la contratación celebrada durante los ejercicios 2010 y 2011 por las entidades estatales que, de acuerdo con la Ley de Contratos del Sector Público, tienen la consideración de Administraciones Públicas; 23 de diciembre de 2013. 
VIÑAS XIFRA, J., "Causas para externalizar servicios en la Administración pública”, en Presupuesto y Gasto Público, no 66, Instituto de Estudios Fiscales, Madrid, 2012, págs. 167 y ss.

VVAA, "Servicios públicos de la Administración local. Abastecimiento de aguas: gestión indirecta y equilibrio económico de los contratos", en Consultor de los ayuntamientos y de los juzgados: Revista técnica especializada en administración local y justicia municipal, $\mathrm{n}^{\circ} 12,2010$, págs. 1851 y ss. 